\begin{tabular}{|c|l|}
\hline Title & In-Plane Shear Performance of Masonry Walls after Strengthening by Two Different FRPs \\
\hline Author(s) & Rahman, A taur; Ueda, Tamon \\
\hline Citation & $\begin{array}{l}\text { Journal of compositesfor construction, 20(5), 04016019 } \\
\text { https://doi.org/10.1061/A SCE)CC.1943-5614.0000661 }\end{array}$ \\
\hline Issue Date & 2016-10 \\
\hline Doc URL & http://hdl.handle.net/2115/63553 \\
\hline Type & article(author version) \\
\hline File Information & A SCE_1531_Final.pdf \\
\hline
\end{tabular}

Instructions for use 


\section{In-Plane Shear Performance of Masonry Walls after Strengthening by Two Different FRPs}

Ataur Rahman ${ }^{1^{*}}$ and Tamon Ueda ${ }^{2}$

Abstract: The present experimental study was aimed to investigate the in-plane shear performance of externally strengthened masonry walls using two types of fiber reinforced polymer (FRP) sheets- CFRP (Carbon fiber reinforced polymer) and PET-FRP (Polyethylene Terephthalate) sheets. Among these two, PET-FRP has a low tensile strength but possess a higher fracturing strain than CFRP. Twelve masonry walls made from clay brick were tested for static lateral loading under constant compression, after bonding CFRP and PET-FRP sheets onto their surfaces in three different configurations. The ultimate shear strength and deformation at peak load were the two important observations. The mechanisms by which load was carried were observed, varying from the initial uncracked state, to the final, fully cracked state. The results demonstrate that a significant increase in the in-plane shear capacity of masonry can be achieved by bonding these two FRPs to the surface of the walls but ductility is compromised when CFRP is used. Walls retrofitting with PET-FRP in a cross-diagonal fashion show a good ductile behavior in both pre-peak and post-peak regimes. The experimental data were used to assess the effectiveness of the strengthening of one FRP over the other. PET-FRP in diagonal configuration was found to be the most effective way of strengthening without compromising the two most essential aspects of masonry i.e strength and ductility.

Keywords: Masonry; Shear wall strengthening; CFRP and PET-FRP sheets; Static shear test.

\section{INTRODUCTION}

Recent earthquakes in Nepal and elsewhere in the world have caused an extensive damage in large number of existing unreinforced masonry (URM) buildings. The majority of those URM buildings have been constructed with little or no attention to seismic considerations. This has resulted in a large inventory of buildings that lack ability to withstand strong seismic jolts. Therefore, there is an urgent need to improve the performance of URM structures by retrofitting and strengthening them to resist potential earthquake damage.

Seismic performance of these structures largely dependents on the strength and behavior under in-plane loading. However, the behavior of masonry walls under in-plane loading can generally be divided into two categories, shear, and flexure. Whether a wall is dominated by shear or flexure is largely dependent on the aspect ratio $(L / H)$ and vertical compression on the masonry $\left(\sigma_{n}\right)$. For slender walls ( $L / H$ less than 1.0$)$ with relatively light axial stress, behavior is usually dominated by flexure and the strength is limited by either rocking or toe-crushing preceded by a flexural cracking. For stocky walls ( $L / H$ greater than 1.5$)$ with moderate to heavy axial stress, shear usually

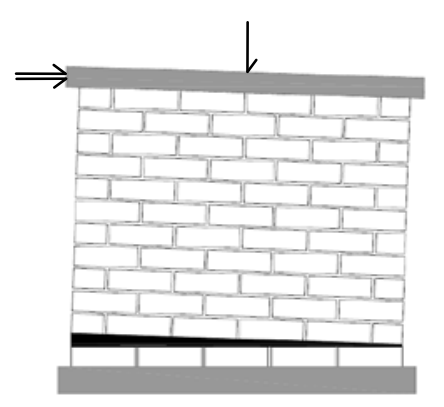

(a) Flexural cracking

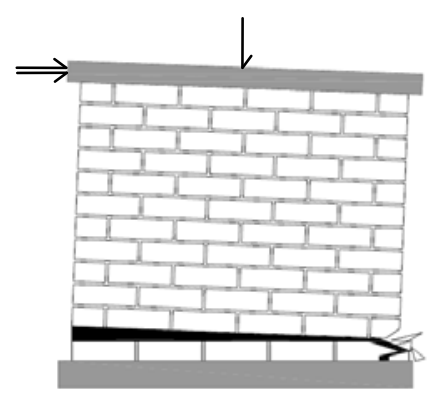

(b) Rocking followed by toe crushing

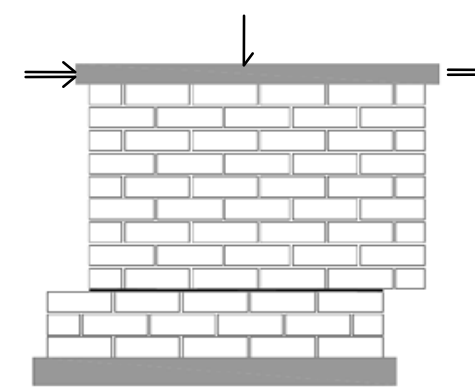

(c) Shear sliding

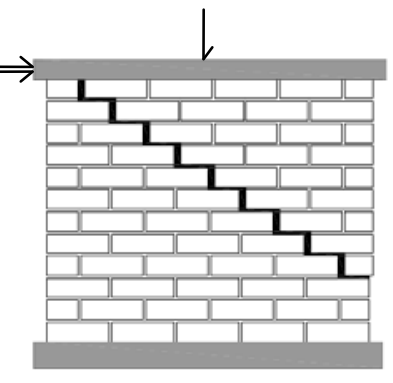

(d) Diagonal tension

Fig. 1. Different Failure modes of URM

\footnotetext{
* Corresponding author: Email: ataur107@yahoo.com

${ }^{1}$ JSPS RONPAKU Fellow, Graduate School of Engineering, Hokkaido University, Japan

${ }^{2}$ Professor, Faculty of Engineering, Hokkaido University, Japan
} 


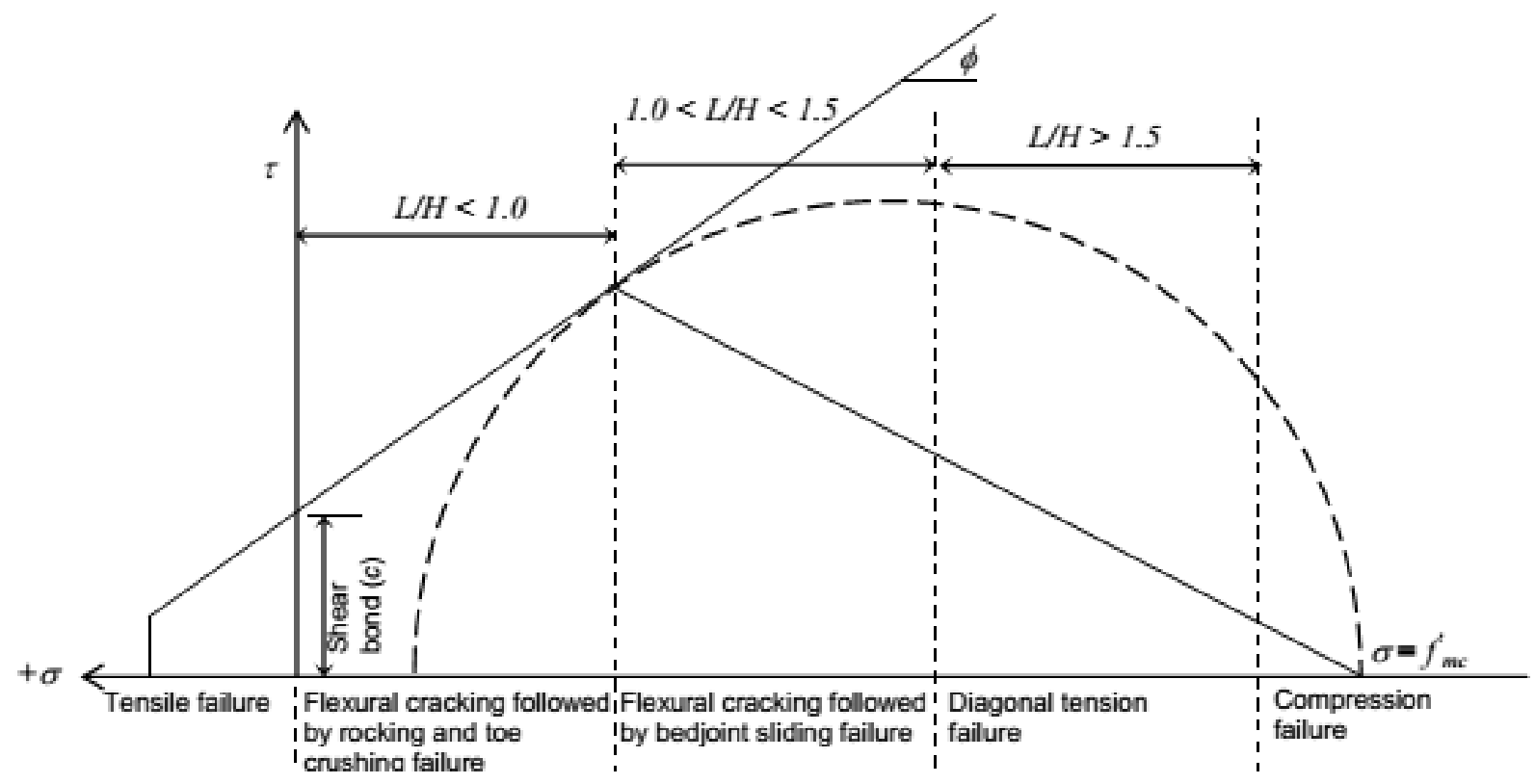

Fig. 2. Generalized behavior of URM under combined shear and normal stress

dominates through bed joint sliding or diagonal tension modes of failure (Magenes and Calvi 1997, Zhuge 2010, Tomaževič and Gams 2009). Among these four inelastic failure modes (Fig.1), rocking and sliding shear are classified as deformation controlled phenomena because large lateral deformation of walls and piers is possible without a significant loss in strength (Foraboschi 2009). In contrast, diagonal tension and toe crushing behavior modes are known as force controlled phenomena because the ultimate failure can be abrupt with little or no subsequent deformation. Stair-stepped diagonal cracking can also be considered as a deformation controlled action because frictional forces along bed joints are conserved with vertical compressive forces. However, diagonal tension cracking must be classified as a force-controlled action unless stair-stepped cracking can be distinguished from diagonal cracking through units (FEMA 274, 1997). It should be noted that not all these failure modes will involve collapsing of the masonry shear wall, and the final failure may be a combination of several failure modes. A more general way of representing the various failure modes of masonry shear wall is given in Fig. 2, where the interactions between normal and shear stresses on the masonry bed joints are shown. It is evident in Fig. 2 that the failure modes in masonry shear walls are generally dictated by the magnitude of vertical compression force applied over the wall. However, a rationally developed failure criteria should be able to predict the tensile, compressive and shear types of failure.

FEMA 356 (2000) provides most up-to-date guideline for analysis of masonry structures considering performance-based design. Three performance levels are defined and used as discrete points to guide a rehabilitation design based on the expected performance of a building. Performance levels are based on the amount of damage to both the structural and non-structural elements. The three defined levels for primary structural elements are Immediate Occupancy (IO), Life Safety (LS) and Collapse Prevention (CP). The guideline states two procedures for determining the acceptability of URM walls as a function of these performance levels, they are Linear Static Procedure (LSP) and Nonlinear Static Procedure (NSP). For any of the procedures, a load-deformation backbone curve is required to determine the strength and expected level of performance of the component. Detail description of

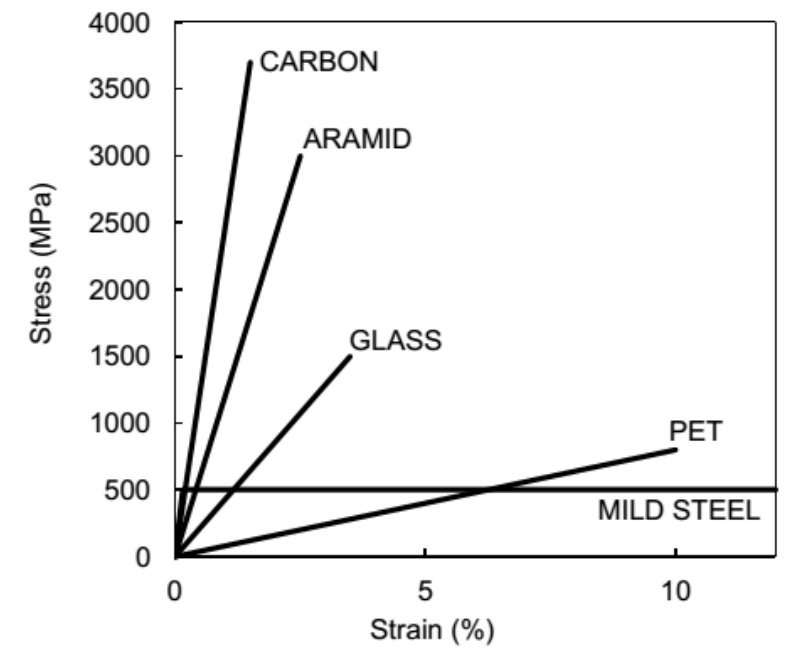

Fig. 3. Tensile strength of different FRPs 
these procedures can be found in Chapter 3 and 7 of FEMA 356. However, design guidelines based on component performance for FRP retrofitted masonry wall are still lagging and this study aims to spot light on this backdrop to some extent.

The aim of seismic retrofitting is to upgrade the ultimate strength/deformation of the structure by improving the structure's ability to undergo inelastic deformation without fully collapsing during an earthquake. Fiber reinforced polymer (FRP), which is a composite material consisting of a polymer matrix imbedded with high-strength

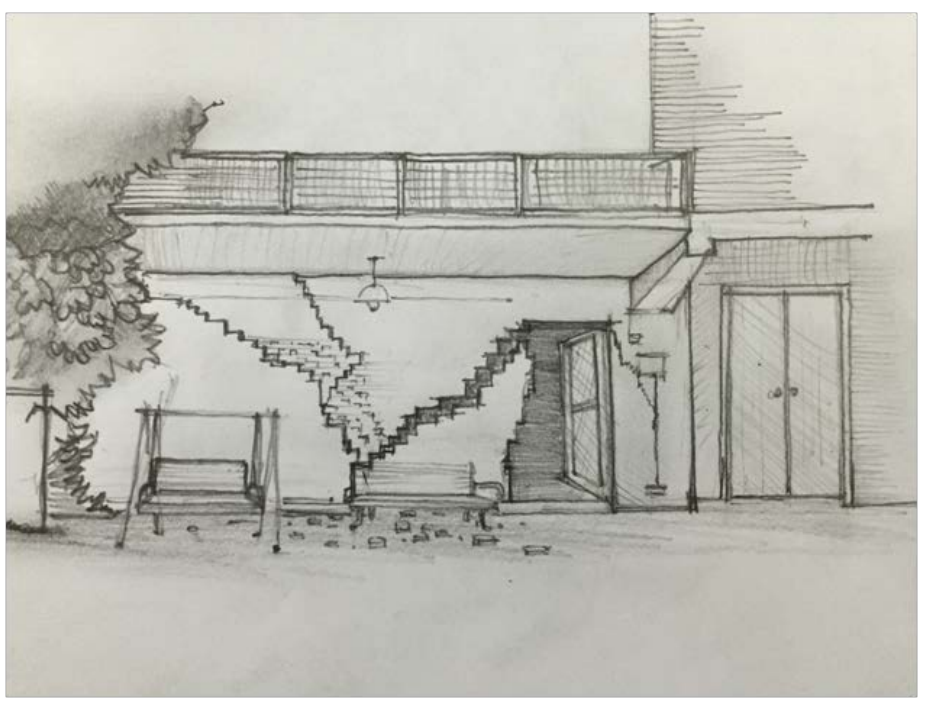

Fig. 4. Typical diagonal tension failure in a squatting wall during Emiliana Earthquake in Italy, 2012

fibers, such as Glass, Aramid, Carbon, etc (Fig. 3) to achieve certain properties better than either of the base materials, is getting popular for retrofitting of the existing masonry structures. The benefit of using FRPs as potential strengthening material comes from the reduction in handling costs; despite additional material costs, and they are easy to install due to light weight (Burgoyne and Balafas 2007). Externally bonded PET-FRP with a large fracturing strain (more than 10\%) is a retrofitting technique that has drawn significant attention as a unique alternative to CFRP or GFRP. High fracturing strain in PET-FRP yields substantial inelastic deformation in masonry which compensates the inherent brittleness of these structures, without compromising the other advantages of FRP. In Japan, the use of PET-FRP has emerged as an alternative to traditional FRPs, such as carbon and glass FRP, where ductility is a major concern than strength (Anggawidjaja et al. 2006).

Various approaches have previously been undertaken to investigate masonry strengthened with FRPs. There is no harmonized test method available to determine the shear performance of masonry elements under lateral loading (Bosiljkov et al. 2008, Tomaževič and Gams 2009). A TNO report (TNO 2004) gives an exhaustive discussion and literature review of various methods for testing of masonry shear wall, that have been undertaken by different researchers. None of them simulate real-time behavior, but have been chosen because they reproduce static or kinematic boundary conditions, which can be easily interpreted with a perceived analytical model. Stratford et al. 2004 tested masonry walls strengthening with GFRP sheet, which shows a considerable increase (65\%) in shear capacity without significant improvement in ductility. In these masonry walls, the failure was primarily attributed to debonding of the GFRP sheet. Alcaino and Santa-Maria (2008) applied CFRP strips in two different configurations over 16 masonry walls. An alternative to this system is to attach the FRP strips over the surface of the wall in a diagonal fashion (Dizhur et al. 2013; Akin et al. 2014; Altin et al. 2007) or in a grid system (Benedetti and Steli 2006). The FRP strips here act as a truss made from unidirectional fibers.

When FRPs are bonded to the surface of the wall, diagonal tension failures or compressive crushing failures at wall toe are quite common (Hamid et al. 2005; Wang et al. 2006). Also, premature debonding of FRP, a brittle but unavoidable failure mode, was commonly observed during the test and, in general, FRP could not reach its ultimate strength (Ehsani et al. 1997; Stratford et al. 2004; ElGawady et al. 2005; Foraboschi and Vanin 2013). Experimental tests indicate that the failure patterns are affected by but not limited to the strength, orientation, amount and anchorage length of FRP (Alcaino and Santa-Maria 2008; Marcari et al. 2007). Long-term durability of FRP strengthening work is a great concern of modern-day researches. One new finding that affects both masonry and concrete members that are externally strengthened using FRP, is delayed debonding, which is a phenomenological development of critical crack throughout the life-time of the structure along the substrate-FRP interface that causes the external FRP to lose bond stress and eventually reduce the lifetime of strengthening works 

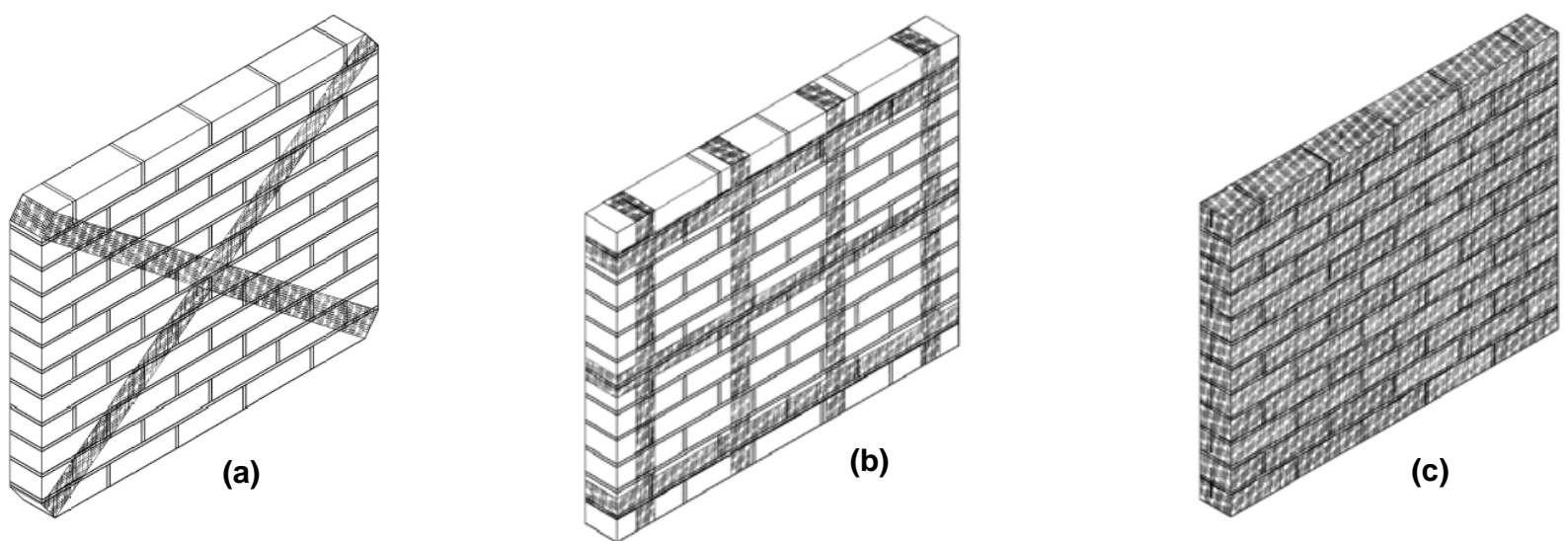

Fig. 5. FRP reinforcement layout, (a) FRP cross diagonal bracings (CSD, PSD); (b) FRP strips in grid system (CSG, PSG); (c) Fully wrapped by FRP (CSF, PSF)

(Foraboschi 2015). Shrestha et al. (2014) pointed out that there is considerable influence of moisture in deteriorating the bond property and reduce the durability of FRP retrofitted works. In general, the possible failure mode for masonry strengthened with FRP can be a combination of several mechanisms such as, excessive cracking due to tensile stresses in the wall, crushing of masonry in the compression zone, shear-slip of masonry, FRP debonding (instantaneous and delayed), and FRP rupture (CNR DT200 R1/2013).

In this study, PET-FRP and CFRP have been used as two distinct strengthening materials. The strength of CFRP is higher than PET-FRP, whereas PET-FRP posses a relatively higher fracturing strain than CFRP. The purpose of this study is to show the difference in behavior of masonry shear walls strengthened by these two different FRPs and the superiority of the one FRP over the other. Ultimate load bearing capacity, deformation at peak load, and mode and mechanism of failure, are observed in this study for different arrangements of the FRPs.

\section{EXPERIMENTAL PROGRAM}

\section{Specimen details}

In this experimental study, a total of 12 masonry walls having a nominal dimensions of $1270 \times 1020 \times 120 \mathrm{~mm}$, were fabricated. All of the walls were made with single layer running bond of bricks having a dimensions of $240 \times 120 \times 74 \mathrm{~mm}$ with an average compressive strength of $30 \mathrm{MPa}$. A $10 \mathrm{~mm}$ thick mortar joint with a compressive strength of $22 \mathrm{MPa}$ was used throughout. Due to the anchorage at the wall top and bottom, the topmost and bottommost layers of the brick were ineffective in transferring the shear. So, the effective height $(872 \mathrm{~mm})$ of the wall comprised of the remaining ten courses of brick, offered an aspect ratio $(L / H)$ of 1.45 .

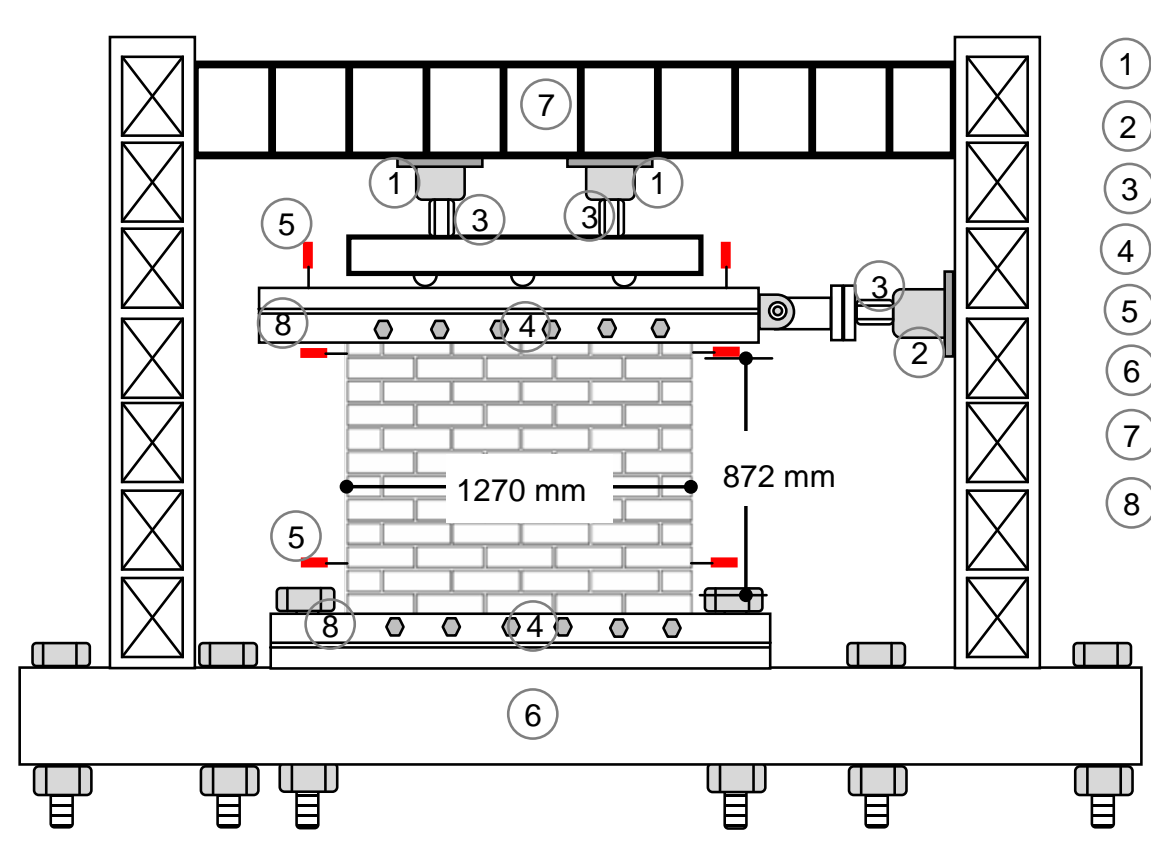

Fig. 6. Schematic diagram of experimental setup of shear wall
(1) Vertical actuator

(2) Lateral actuator

(3) Load cell

(4) $22 \mathrm{~mm}$ bolt

(5) LVDT

6) Reaction floor

(7) Reaction frame

8) Channel beam

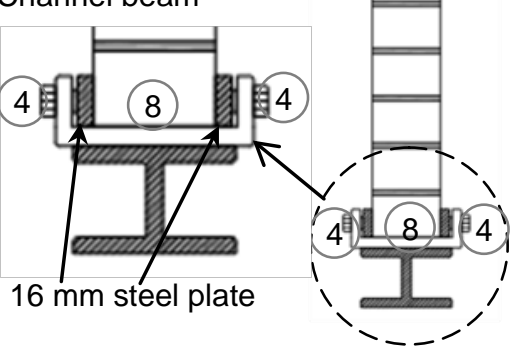

$X$-sec. view 
Though the size of the masonry wall chosen for this experimental purpose does not necessarily reflect the nominal size of actual masonry structures, an aspect ratio of 1.45 does resemble that of the real time masonry shear wall as failure in this size of wall predominantly governed by either bed joint shear sliding or diagonal tension failure [Figs.1(c) and (d)], which can be seen in many masonry failure during the past earthquakes (Fig. 4). Table 1 gives the details of the walls. In this table, RW stands for Reference Wall, P for wall strengthening with PET-FRP, C for wall strengthening with CFRP, D for Diagonal strip configuration, G for Grid system, F for Fully wrapped wall and S for Solid bricks.

\section{Specimen preparation}

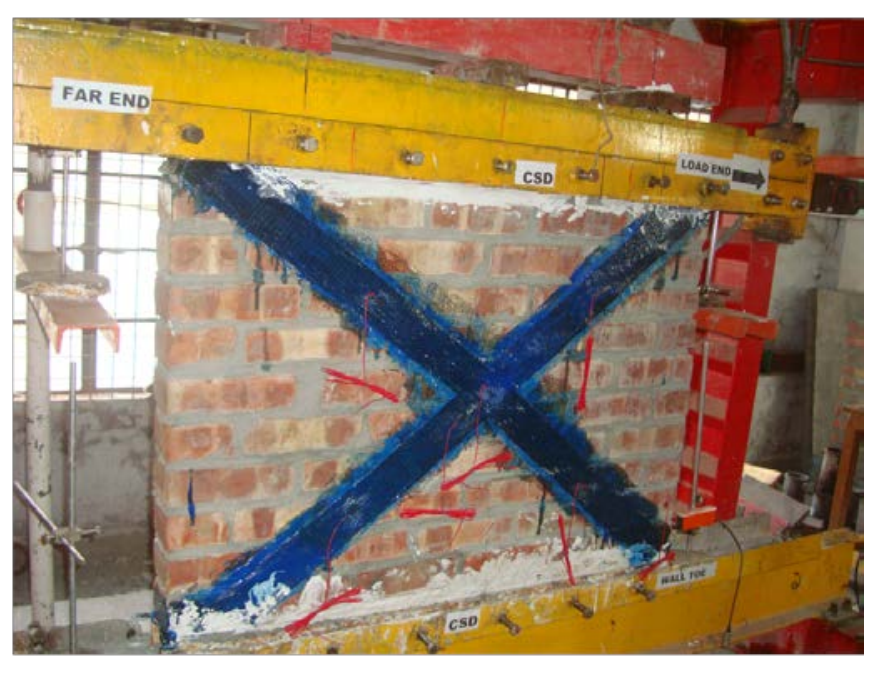

Fig. 7. Experimental setup of FRP reinforced masonry panel

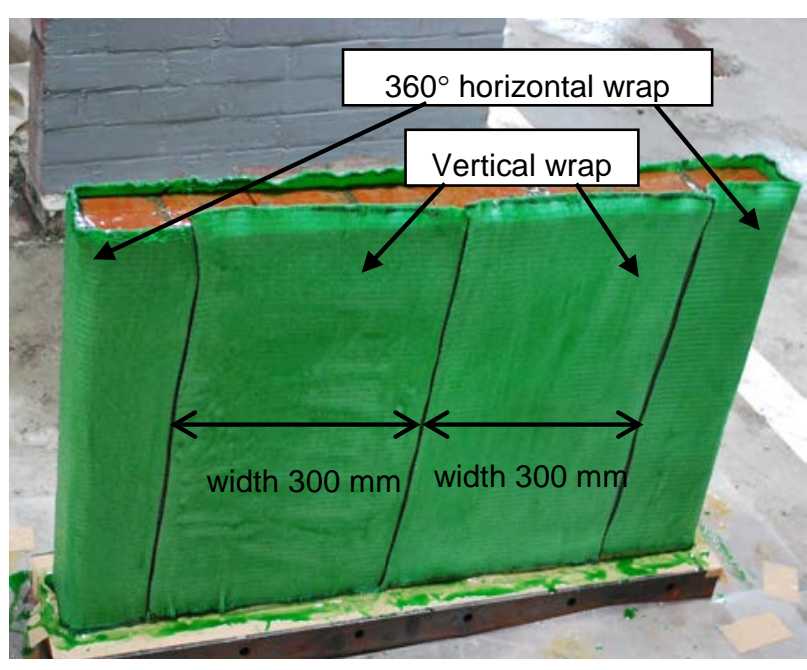

Fig. 8. FRP installation in fully wrapped wall

PET-FRP and CFRP sheets both having unidirectional fibers, were applied using a wet layup procedure on wall specimens in three different configurations as shown in Fig. 5. At first, the wall specimens were cleaned by removing loose mortar and dirt with the help of a wire brush. Epoxy putty (filler) was used to fill the depression on the wall surface to provide a smooth plane surface ready for FRP laying. A thin layer of primer was then

Table 1. FRP Configurations and Summary of Test Results

\begin{tabular}{|c|c|c|c|}
\hline Wall ID & $\begin{array}{l}\text { Peak Load } \\
\qquad(\mathrm{kN})\end{array}$ & $\begin{array}{l}\text { Def. at Peak } \\
\text { Load (mm) }\end{array}$ & $\begin{array}{c}\text { FRP } \\
\text { configuration }\end{array}$ \\
\hline \multirow[t]{2}{*}{ RWS1 } & 48 & 8.7 & \\
\hline & & & Reference wall \\
\hline RWS2 & 30 & 5.4 & \\
\hline \multirow[t]{2}{*}{ PSD1 } & 114 & 8.9 & \\
\hline & & & PET cross diagonal \\
\hline PSD2 & 101 & 24.7 & \\
\hline \multirow[t]{2}{*}{ PSG1 } & 129 & 10.0 & \\
\hline & & & PET in grid system \\
\hline PSG2 & 88 & 9.7 & \\
\hline PSF & 168 & 6.5 & PET fully wrapped \\
\hline CSD1 & 95 & 2.9 & Carbon cross \\
\hline CSD2 & 94 & 4.4 & diagonal \\
\hline CSG1 & 134 & 2.5 & Carbon in grid \\
\hline CSG2 & 99 & 7.0 & system \\
\hline CSF & 107 & 2.7 & Carbon fully \\
\hline
\end{tabular}

applied all over the wall to seal the pores in the masonry. Epoxy resin having the properties indicated in Table 2 was then applied over the wall wherever necessary. Fiber sheets were cut to the width of 80 $\mathrm{mm}$ for diagonal strip and $70 \mathrm{~mm}$ for grid system. Resin was then applied with a roller brush all over the sheet strip so that it was fully saturated by the resin. As soon as the application of the resin was completed, the FRP strips were laid over the wall and wrapped tightly to keep them in place. For the diagonal strip, the wall corners were cut in the same dimension width (80 mm) as the strip [Fig. 5(a)] in order to avoid sharp edges and problem in wrapping.

\section{FRP anchorage}

After the required curing period, the wall was transferred to the loading frame as shown in Fig. 6, specially designed for this experimental study. The wall top and bottom were anchored to the top and bottom channel beams, with the help of twenty four 22 

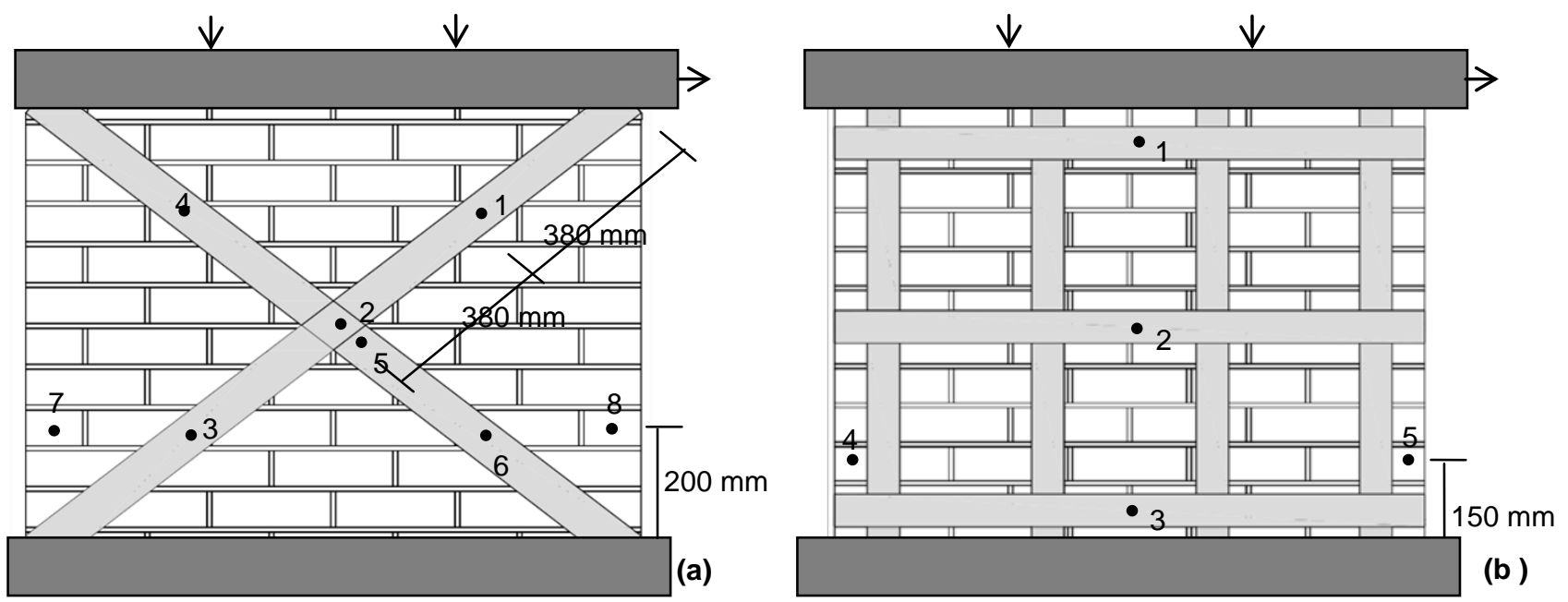

Fig. 9. Strain gauges layout (a) cross digonal layout (b) grid layout

mm bolts as shown in Figs. 6 and 7. Between the wall and the channel beam, a 16mm thick steel plate was inserted so that pressure could be applied on the wall by tightening the bolts. Gypsum plaster was used to fill the gap between the wall and the steel plate. For FRP strengthened walls, the FRP itself was wrapped in a U-shape anchorage, so there was almost no chance of slippage of the FRP during the experiment. Although this kind of anchorage system is not very much practical for the real structure, it has been chosen so for this experimentation to avoid premature anchorage failure of FRP prior to attaining full shear strength. For fully wrapped masonry walls,

Table 2. Properties of FRPs and Adhesives

\begin{tabular}{lllll}
\hline & \multicolumn{2}{l}{ FRP materials } & \multicolumn{2}{l}{ Adhesive materials } \\
\cline { 2 - 5 } Properties & PET & CFRP & RESIN & PUTTY \\
\hline Tensile strength (MPa) & 740 & 3400 & 45 & 20 \\
Elastic modulus (GPa) & $10 \pm 1$ & 245 & 1.56 & - \\
Elongation at fracture (\%) & $10 \pm 1$ & 1.5 & 28 & - \\
Thickness (mm) & & & & - \\
Width (mm) & 0.841 & 0.111 & & - \\
\hline
\end{tabular}

Source: $\quad$ Nippon Steel \& Sumikin Materials Co. Ltd. Japan and Maeda Kosen Ltd. Japan. horizontal FRP sheets were installed on the wall in $360^{\circ}$ wrapping (Fig. 8) and vertical sheets were anchored to the top and bottom channel beams with $22 \mathrm{~mm}$ bolts as shown in Fig. 7.

\section{Application of Load}

A pre-compression of $40 \mathrm{kN}$ which is equivalent to a uniform pressure of $0.25 \mathrm{MPa}$, was applied on the top of the wall through two hydraulic jacks,

prior to incrementally increasing lateral loading (Fig. 6). Lateral load was applied gradually, increasing at a constant rate of $5 \mathrm{kN} / \mathrm{min}$ until it reached at peak. In post-peak regime, a constant displacement of $2 \mathrm{~mm} / \mathrm{min}$ was applied until complete failure. The two vertical loads restricted the rotation of the top beam only to some extent, as the beam was not restrained against rotation during the evolution of lateral load. A fixed-free experimental condition was maintained throughout the loading process.

\section{Instrumentation and Data Acquisition}

Sufficient number of uniaxial, biaxial and rosette strain gages, LVDTs, and load cells (50 tons capacity) were used to record all the necessary information during the testing (Fig. 9). A lateral load was applied in a pull-out manner by a 50-ton capacity center-hole jack, with a remote pump, until the complete failure of the masonry wall. All of the data (displacement, strain, and load) were recorded through a digital data logger. 


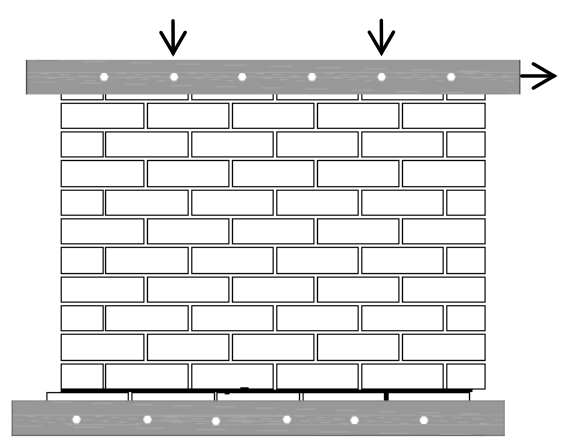

(a) RWS1

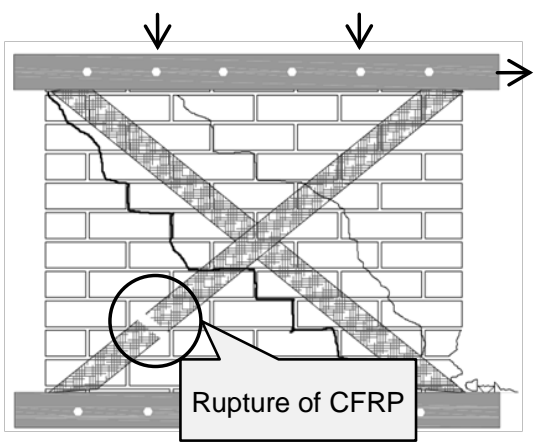

(d) CSD2



(b) RWS2

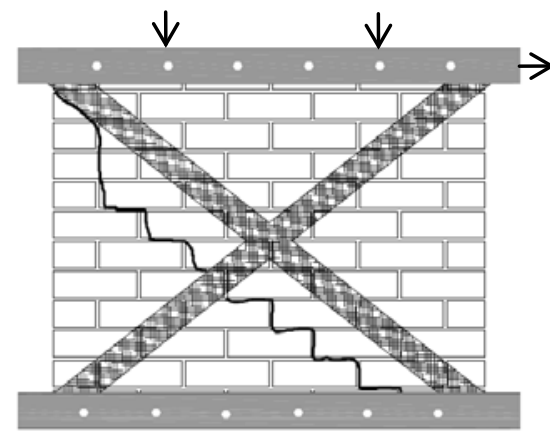

(e) PSD1

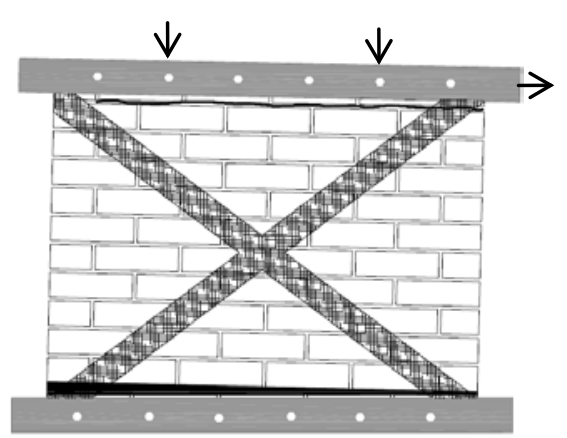

(c) CSD1

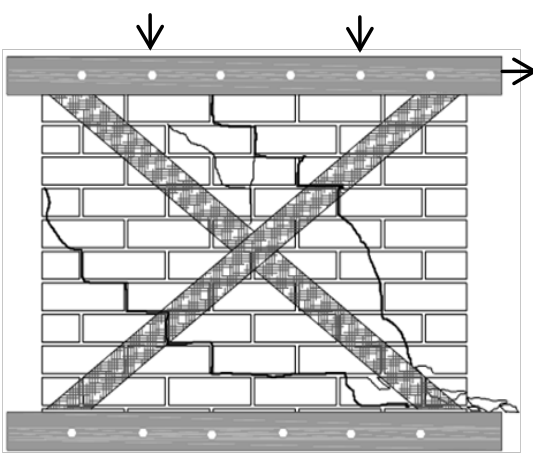

(f) PSD2

Fig. 10. Schematic illustration of crack patterns in unreinforced and FRP retrofitted masonry panels

\section{EXPERIMENTAL OBSERVATION}

\section{Failure of URM walls (RWS1, RWS2)}

These two reference specimens were tested under similar boundary conditions to make a comparison with rest of the walls mentioned in Table 1. No potential crack was observed in either of the walls until the load reached about $80 \%$ of the peak load. Only after that a flexural crack appeared at the heel of the wall, and propagated towards the toe as shown in Figs. 10(a) and (b), and the load dropped slightly. Lateral load was further increased to ultimate load, and the crack opening widened as the crack propagated all the way to the toe of each wall. After the applied load reached its peak, it did not decrease much with the increased displacement, which furthered the shear-slip along the crack plane for wall RWS1 [Fig. 10(a)]. In specimen RWS2 no shear-slip was observed rather the crack propagated in a stepped fashion and travelled all the way to the toe and a faster crushing at the wall toe was observed which caused a rapid decrease in load. This kind of failure in URM wall under shear is reported in a number of papers (Stratford et al. 2004; Salmanpour et al. 2013; Bosiljkov et al. 2003; ElGawady et al. 2007 etc).

\section{Failure of FRP reinforced walls}

\section{Diagonally braced Walls (CSD, PSD)}

These four walls were externally strengthened by two diagonal CFRP and PET-FRP strips each, of 80 mm in width in a fashion shown in Fig. 5(a). No noticeable crack appeared on either of the wall until the lateral load reached about $75 \%$ of the ultimate strength. In the case of the wall CSD1 two flexural cracks appeared at the wall top on the loading end and at the wall bottom on the far end [Fig.10(c)] followed by some debonding of the CFRP tension diagonals. No rupture or damage of the CFRP was observed. For wall CSD2, some fine line cracks appeared at the top of the wall on far end and started to propagate downward in a stepped fashion. Almost simultaneously another crack, parallel and above to this one appeared and began to propagate downward in a same manner but with a lesser degree of crack opening displacement. Once the load increased to a maximum of $94 \mathrm{kN}$, a sudden rupture of the diagonal tension strip on the both sides of the wall took place and the load suddenly dropped to the half of the peak load. Accumulated compressive stress caused some crushing at wall toe just before the rupture of the CFRP strip which can be seen Fig. 10(d). 
In the case of the walls reinforced with PET-FRP strips (PSD1 and PSD2), at a load of nearly 50\% of the peak load, similar diagonal cracks were observed being appearing on these two walls along the bottom of the compression diagonal and traversed along the compression diagonal in a stepped fashion [Figs. 10(e) and (f)]. In PSD2, another crack appeared on the top of the compression diagonal and propagated all the way to the toe of the wall followed by some toe crushing. The peak loads of $114 \mathrm{kN}$ and $101 \mathrm{kN}$ respectively were not attenuated much with the applied displacement for quite a long time, and at that stage the experiment was ceased. Some debonding in tension diagonal PET strips was observed in both of these two walls.

\section{Wall strengthened by FRP grid system (CSG, PSG)}

These four walls were strengthened with CFRP and PET-FRP strips of having $70 \mathrm{~mm}$ width each in a grid system as shown in Fig. 5(b). In the case of the CFRP reinforced wall (CSG1), at a load, amounting to 70\% of peak load, some fine-line diagonal cracks appeared at the central area of the wall. More cracks appeared across the tension diagonal with simultaneous debonding of the CFRP strips, while the load reached at a level of $130 \mathrm{kN} \mathrm{[Fig.} \mathrm{11(a)].}$ Almost simultaneously, one of the horizontal CFRP strips ruptured with a loud explosive sound, and the load dropped to $109 \mathrm{kN}$. With further displacement, the crack width increased and, in some places, the CFRP totally separated from the wall. In CSG2, at a load equal to about 75\% of the peak load, flexural crack along the bottom of the wall appeared and followed by another flexural crack at the mid-height of the wall and a web crack at the center [Fig. 11(b)]. With further displacement the peak load did not change from $99 \mathrm{kN}$, which only widened the crack opening. No rupture of CFRP was noticed, except some debonding in horizontal strips at few places.

For PSG1, at a load of about $120 \mathrm{kN}$ which is tantamount to $93 \%$ of the peak load, some debonding of the PET-FRP strip occurred along the tension diagonal. Almost simultaneously, a flexural cracking followed by some discontinuous diagonal cracking appeared at the lower half of the wall on the heel side, and travelled all the way to the wall toe in a stepped fashion as shown in Fig. 11(c). Similar but a single flexural crack was observed in the wall PSG2 at a load of 63 kN, as shown in Fig. 11(d). Minor crushing at wall toe was noticed as soon as the peak load reached at $88 \mathrm{kN}$.

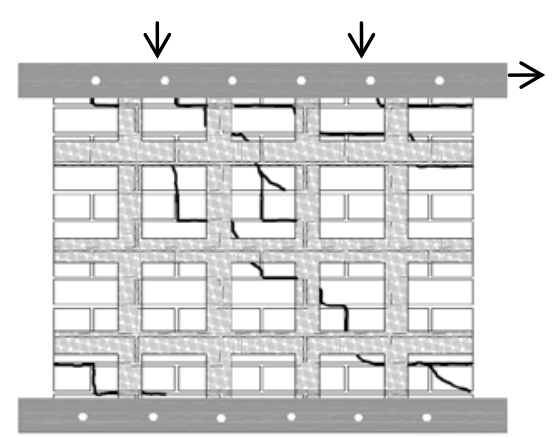

(a) CSG1

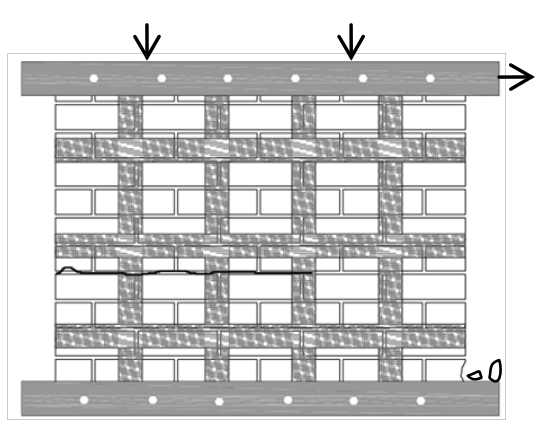

(d) PSG2

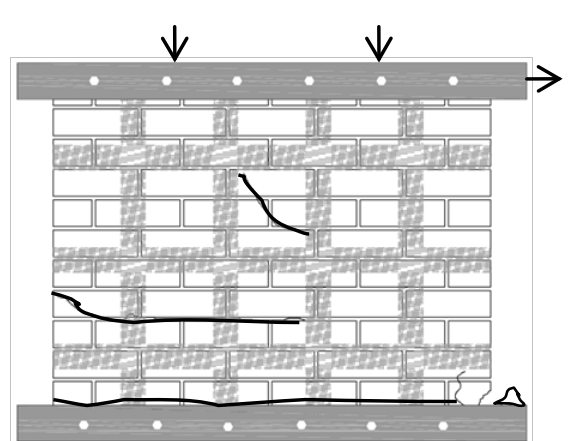

(b) CSG2

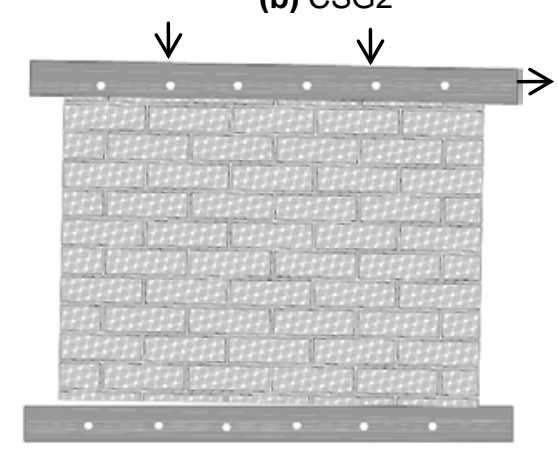

(e) CSF

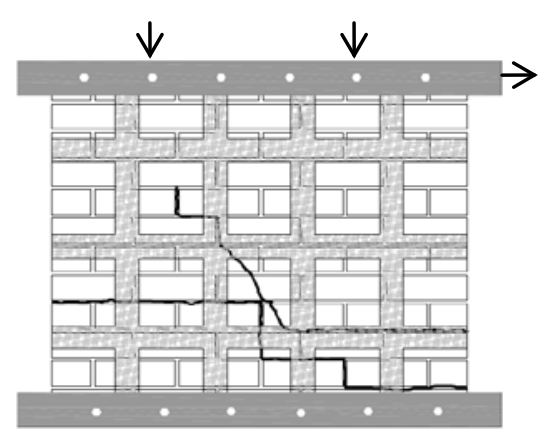

(c) PSG1

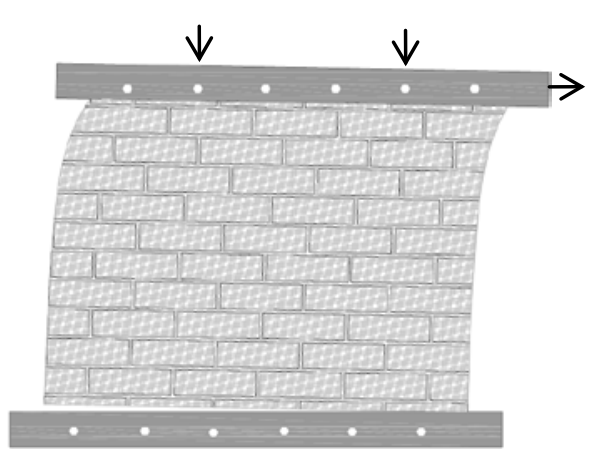

(f) PSF

Fig. 11. Schematic representation of crack patterns in grid system and fully wrapped panels 


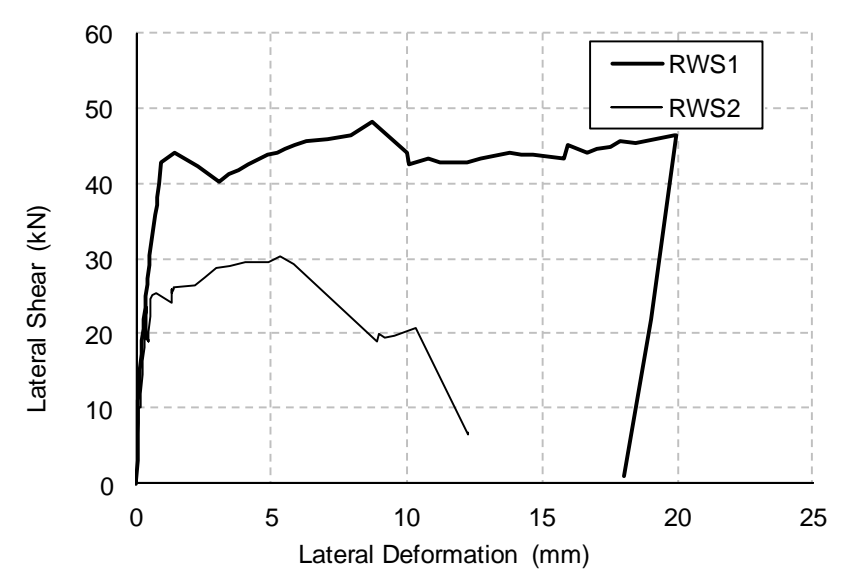

(a) Reference panel RWS1 and RWS2

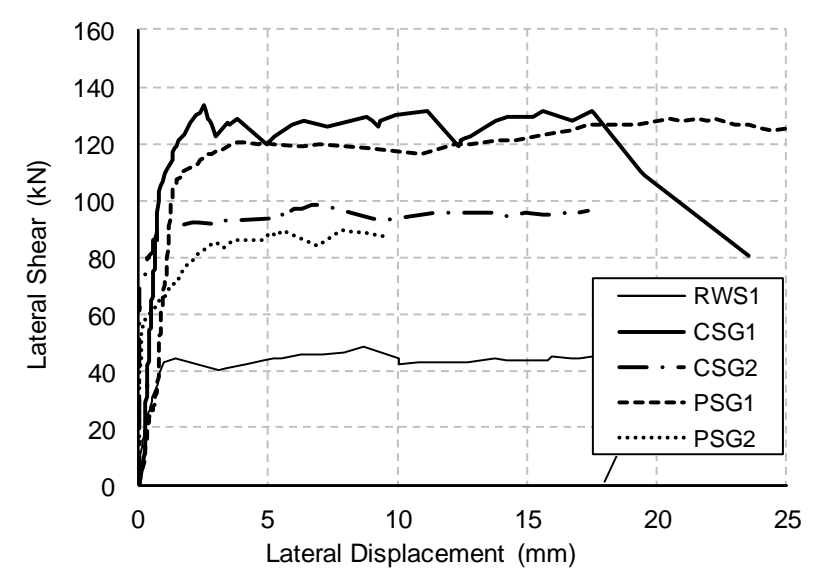

(c) Panels CSG and PSG with FRP grid system

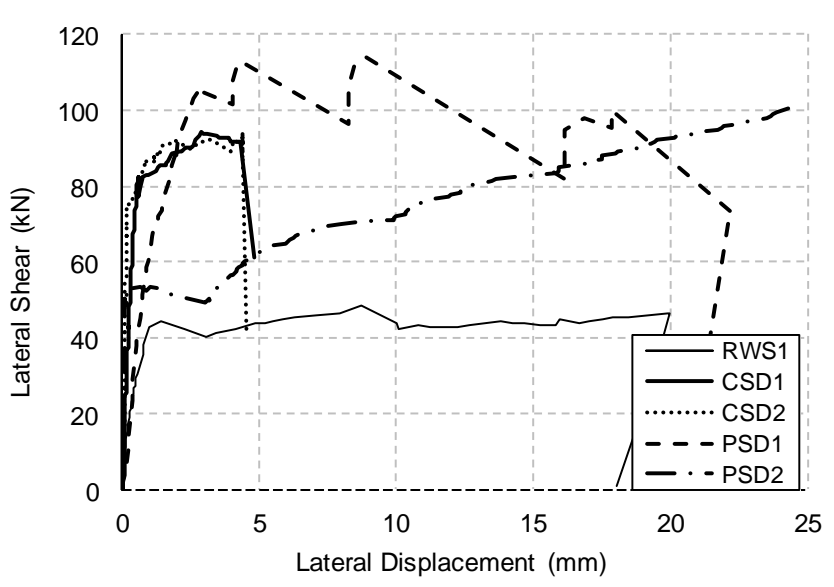

(b) Panels CSD and PSD with diagonal FRP

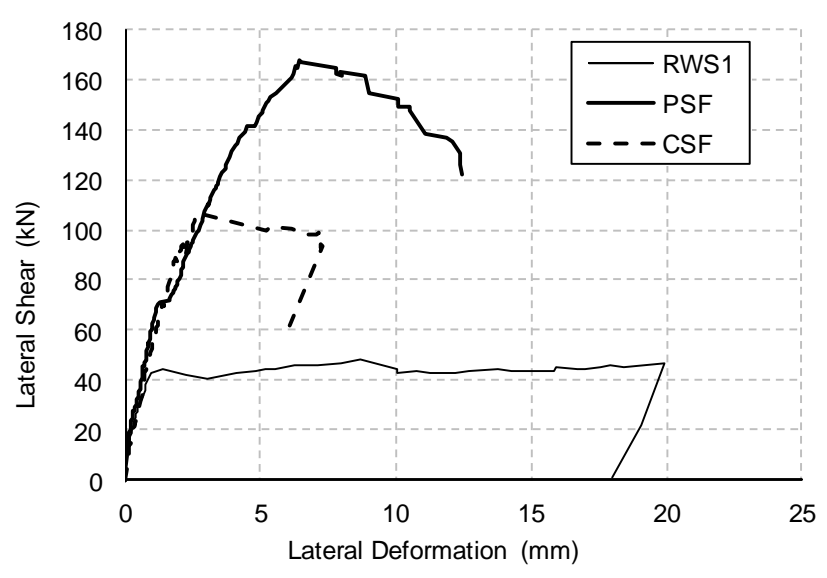

(d) Panels CSF and PSF with fully wrapped FRP

Fig. 12. Load-deformation responses of unreinforced and retrofitted masonry shear walls

\section{Walls fully wrapped with FRPs (CSF, PSF)}

These two walls were strengthened after fully wrapped with CFRP and PET-FRP sheets according to Fig. 8. For CSF, the stiffness as well as the lateral load capacity was so high that at a later stage the grip at the wall bottom prematurely failed before the wall attained its full strength [Fig. 11(e)]. Since the wall was fully wrapped by the CFRP sheets, damage, if any, could hardly be detected by visual observation. On the other hand, the wall PSF showed constant stiffness until it reached about $60 \%$ of its peak shear capacity. Only after that, did the stiffness show a reduction, but no damage or crack whatsoever was seen on the wall [Fig. 11(f)]. Once it reached its full strength, further displacement only resulted in load reduction and the wall failed at its grip at the bottom similar to the wall CSF. It was quite clear from fully wrapped wall that higher the percent of FRP higher is the stiffness as well as some enhancement in shear strength of masonry wall. However, higher amount of FRP materials do compromise with the ductility of the wall and are not fitting well with the purpose of seismic strengthening.

\section{Load-deformation response}

\section{Unreinforced masonry walls}

The load-deformation characteristics of reference walls (RWS1 and RWS2) are depicted in Fig. 12(a). It is quite evident from the figure that, before appearance of any potential flexural crack, the load-deformation relationship is almost linear for both the two walls. It is interesting to note that RWS1 shows quite ductile behavior while maintaining a constant lateral strength due to shear slip at the wall bottom. On the other hand RWS2 shows a rapid reduction in lateral shear after a crushing took place at the wall toe.

Fig. 13 shows the variation of vertical pre-compression with the progress of lateral load. It is evident from Fig. 13 that the vertical load on the far-end increased with the progressive shear, while the vertical load went down on loaded-end. This is due to the fact that, with the increase of lateral load, the top beam on the wall underwent a small 
rotation, which exerted a vertical upward pressure on the far-end jack on the wall. However, the average vertical load (broken line in Fig. 13) did not change much from the initial stipulated value of $20 \mathrm{kN}$.

\section{Strengthened masonry walls}

The load-deformation characteristics of diagonally braced walls (CSD and PSD) are plotted in Fig. 12(b). It is quite evident from the figure that, the lateral load capacity increased more than twice for all the four retrofitted walls. The lateral load increased quite linearly until a potential crack appeared in those walls. A reduction in stiffness can

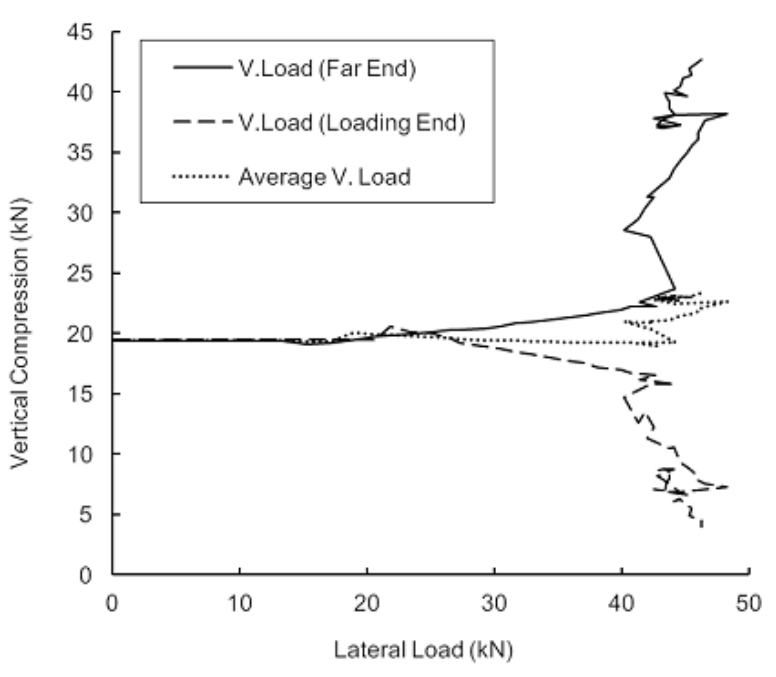

Fig. 13. Variation of vertical load with progressive shear be seen there after which depicts the inelastic response of the strengthened masonry walls. One important characteristic here is that the wall diagonally braced with CFRP strips, shows a brittle type of failure where load reduction was quite abrupt with no softening at all. This was due to the crushing at wall toe immediately followed by a rupture of the tensile CFRP strips on the both side of the wall [Fig. 10(d)]. In contrast, walls strengthened by PET-FRP, show quite ductile nature of inelastic behavior, followed by a gradual softening regime, retaining some residual strength. Moreover, no rupture of the PET strip was observed in PSD walls; expect some debonding phenomenon elsewhere in the tension diagonals.

Fig. 12(c) portrays the load-deformation response of the walls that were strengthened with CFRP and PET-FRP in grid system. Initial stiffness was fairly linear at the beginning and maintained a constant stiffness up to the two-third of the peak load. Only after that a reduction in stiffness can be seen and a ductile nature of inelastic response continued for quite a long time. It is also interesting to note that the ductility is not compromised substantially when the walls are strengthened with higher amount of CFRP such as in grid system than the amount of CFRP in diagonal configuration. This phenomenon also holds true for PET-FRP walls (PSG1 and PSG2) as well.

On the other hand, Fig. 12(d) demonstrates the load-deformation response of the walls fully wrapped by FRPs. The shear capacity of those walls increased by more than three time of that of unreinforced walls. The deformation does not portray the real picture as it was stated earlier that these two walls underwent some rotation at their bottom and a premature failure at the grip followed. Even then, a lesser amount of deformability of these walls can be foreseen from their load-deformation characteristics. However, it can be predicted that wall strengthened with PET sheet behave in a ductile manner than its counterpart CFRP wall and wall strengthened with PET-FRP can resist more lateral load than CFRP wall.

\section{ANALYSIS AND DISCUSSION OF THE EXPERIMENTAL RESULTS}

From the foregoing observation of the experimental results it was evident that the load carrying capacity of the masonry walls subjected to in-plane shear can be greatly increased by applying either CFRP or PET-FRP sheet on their external surfaces, but the ductility of those walls are substantially compromised, once they are bonded with CFRP sheet. It was also observed that the failure modes of the strengthened masonry walls are largely affected by the strength, orientation, and anchorage system of FRP. In the following section more in depth analysis of failure mechanism and in-plane shear resistance are discussed in light of the aforementioned experimental observation and existing knowledge on masonry.

\section{Analysis of unreinforced masonry}

The difference in failure modes for the reference specimens RWS1 and RWS2 can be attributed to the location where the first flexural cracks appeared in these two specimens and their line of propagation [Figs. 10(a) and (b)]. 
In RWS1, first flexural crack appeared at the very bottom course of the wall and propagated horizontally in a straight fashion towards the wall toe [Fig. 10 (a)], which facilitated the wall to slip along the crack path. Once a crack forms at the wall heel, no tension force perpendicular to the crack can be transmitted across it, and the load drops by a little but as long as the crack is narrow, the wall can still transmit some shear forces in its own plane through friction of the surface roughness that can be characterized as elasto-plastic behavior. With further deformation and slip, the interlocking planes suffer substantial damage and are flattened to some extent after which the wall reaches in a state of kinematic equilibrium where only some residual frictional shear resistance prevails (Rahman and Ueda 2014), which does not diminish with the applied displacement as can be seen in Fig 12(a). In reference wall RWS2 first flexural crack appeared three courses above the bottom course on the wall heel side and propagated towards the wall toe in a stepped fashion [Fig. 10(b)]. This failure pattern prompted a rocking phenomenon in the wall instead of shear sliding and consequently a softening behavior was observed in the post-peak regime [Fig. 12(a)] caused by a toe crushing in the wall. It is worth noting here that the location where the first flexural crack will appear is somehow difficult to predict as was the case for these two reference walls. This is largely because of the non-homogeneous nature of masonry fabrication that creates several plane of weakness along the horizontal bed joints.

So, it can be said that an earlier flexural crack normally followed by either a toe crushing or a sliding shear type of failure. Stratford et al. (2004) observed similar failure mode in masonry walls. Moreover, it is quite evident in Fig. 12(a) that the shear strength for masonry sliding is higher than that of rocking and toe crushing because shear sliding endures a resistance along the entire crack plane where as toe crushing occurs due to accumulation of compression stress on a very small area at the crack tip on the wall toe. It is also observed that the existing equations [Eqs. (1) and (2)] proposed by FEMA 356 (2000) to calculate masonry in-plane shear strengths for different modes of failure can fairly approximate the experimental results (48 and $30 \mathrm{kN}$ ) and the predicted results were 47 and $27 \mathrm{kN}$ for RWS1 and RWS2 respectively.

Shear strength for bed-joint sliding:

$$
V_{M}=A_{g} \tau_{s l d}=A_{g}\left(c+\sigma_{n} \tan \phi\right)
$$

Shear strength for toe crushing:

$$
V_{M}=\alpha_{1} \sigma_{n} A_{g}\left(\frac{L}{H}\right)\left(1-\frac{\sigma_{n}}{0.7 f_{m c}^{\prime}}\right)
$$

Some of the parameters used in these equations depend on test results. In absence of candid test results for masonry compressive strength and cohesion Eq. (3) (Eurocode 6, 2005) and Eq. (4) (Ali et al. 2012) can safely be used for a conservative value of these two parameters.

Where,

$$
\begin{aligned}
& f_{m c}^{\prime}=0.55\left(f_{b}\right)^{0.7}\left(f_{m}\right)^{0.3} \\
& c=0.0337\left(f_{m}\right)^{0.6}
\end{aligned}
$$

Here, $V_{M}=$ shear strength of URM wall; $L, H, b=$ length, height and thickness of the masonry wall; $f_{m c}^{\prime}=$ compressive strength of masonry prism; $A_{g}=$ sectional area of wall $=(L \times b) ; \alpha_{1}=$ factor for boundary condition ( 0.5 for cantilever wall and 1.0 for fixed-fixed wall); $\tau_{\text {sld }}=$ average bed-joint sliding shear stress of URM wall; $c=$ cohesion between mortar and brick; $\sigma_{n}=$ vertical compression on masonry wall; $\phi=$ frictional angle at sliding surface (Approx. 20․ Hansen 1999) ; $f_{b}, f_{m}=$ uniaxial compressive strength of brick and mortar respectively.

Considering the ongoing discussion, the following conclusions can be made: 
Table 3. Summary of Test Results for Masonry Walls

\begin{tabular}{|c|c|c|c|c|}
\hline Wall ID & $\begin{array}{l}\text { Peak } \\
\text { Load }\end{array}$ & $\begin{array}{l}\text { Def. at peak } \\
\text { load (mm) }\end{array}$ & $\begin{array}{c}\text { FRP area } A_{f} \\
\left(\mathrm{~mm}^{2}\right)\end{array}$ & $\begin{array}{c}\text { FRP axial } \\
\text { stiffness }\end{array}$ \\
\hline RWS1 & 48 & 8.7 & & \\
\hline RWS2 & 30 & 5.4 & -- & -- \\
\hline PSD1 & 114 & 8.9 & & \\
\hline PSD2 & 101 & 24.7 & 81 & 810 \\
\hline $\begin{array}{l}\text { PSG1 } \\
\text { PSG2 }\end{array}$ & $\begin{array}{l}129 \\
88\end{array}$ & $\begin{array}{l}10.0 \\
9.7\end{array}$ & 353 & 3530 \\
\hline PSF & 168 & 6.5 & 1467 & 14670 \\
\hline $\begin{array}{l}\text { CSD1 } \\
\text { CSD2 }\end{array}$ & $\begin{array}{l}95 \\
94\end{array}$ & $\begin{array}{l}2.9 \\
4.4\end{array}$ & 11 & 2610 \\
\hline $\begin{array}{l}\text { CSG1 } \\
\text { CSG2 }\end{array}$ & 134 & $\begin{array}{l}2.5 \\
7.0\end{array}$ & 47 & 11420 \\
\hline CSF & 107 & 2.7 & 194 & 47430 \\
\hline
\end{tabular}

Note: $A_{f}=$ sectional area of FRP,$E_{f}=$ Elastic modulus of FRP
- Masonry with an aspect ratio $(L / H)$ nearly 1.5 and with a low vertical pressure (0.25 MPa) can have either shear sliding or toe crushing type of failure.

- Shear sliding offer more resistance than toe crushing and the existing FEMA 356 provisions can fairly predict the test results.

- More tests are necessary to observe diagonal tension failure in masonry with the same aspect ratio but with higher vertical stresses.

\section{Analysis of strengthened masonry}

Experimental results summarized in Table 3 illustrate that the in-plane shear capacity of the tested walls was significantly enhanced by the proposed strengthening technique but the ductility behavior was not essentially the same. Figs.10 and 11 depict the crack patterns and failure modes for all the retrofitted walls. It is interesting to see that the mode of failure in masonry when they are strengthened with diagonal FRP, is

diagonal tension and they are quite similar to each other (except for the case of CSD1, where there might be high possibility that the anchorage at the bottom of the diagonal tension strip was somehow loosen that prompted a flexural tension cracking). Bonding FRP material onto the surface of the walls in diagonal fashion made it stronger against flexural cracking due to the tied-action of the FRP tension diagonals and triggered a diagonal cracking along the compression diagonal. Accumulated compression stresses at the toe region of the wall eventually caused a toe crushing and to some extent ruptured the CFRP tension diagonal as for the case of wall CSD2. Though there is not much difference in shear strength among these four walls, significant difference can be noticed in deformation capacity. Table 3 shows that the FRP stiffness in CFRP diagonal is three times more than that of PET-FRP diagonal, but the mean deformation at peak load is only one-fifth of PET-FRP strengthened wall. This is due to the fact that PET possesses a higher fracturing strain (more than six times) than CFRP (see Table 2). It is worth noting here that high stiffness not necessarily offers high shear strength, rather the reverse is very likely. Another interesting thing here is that the stain in FRP remains quite low before the inception of any potential cracking in masonry. Once there is a crack, the internal stress is redistributed and shifts its position from masonry to FRP, thus increase the strain in FRP, especially in tension diagonal strips as illustrated in Fig. 14. During that time, debonding phenomenon was also observed in FRP that resulted a fluctuation in distribution of internal strain in FRP. It is also important to mention here that even at the time of masonry failure when the lateral load reaches its peak; the effective strain remains quite low and amounting to only some fraction of the ultimate fracturing strain of FRP. Based on this principal, most of the analytical models assume a low value of effective strain in FRP while calculating the shear contribution by FRP (CNR DT 200 R1/2013, ACI440). These phenomena hold true for both CFRP and PET as well. Therefore, many authors (Stratford et al. 2004, Marcari et al. 2007) argued that it is impossible to accurately predict the FRP contribution to shear strength as they prove by their experimental test that the contribution of the FRP to the shear strength of masonry wall is far less than its ultimate tensile strength. So, it can be concluded that, 
- The mode of failure in masonry may change from shear sliding to masonry diagonal cracking when they are externally strengthened by FRP diagonal strips.

- FRP with high elastic modulus and low fracturing strain such as CFRP offer less ductility and possibly less in-plane shear strength, which is not a good option for masonry strengthening.

- PET-FRP shows good ductile behavior at both pre-peak and post-peak regimes and significantly enhances masonry shear capacity.

- FRP debonding is a common phenomenon for

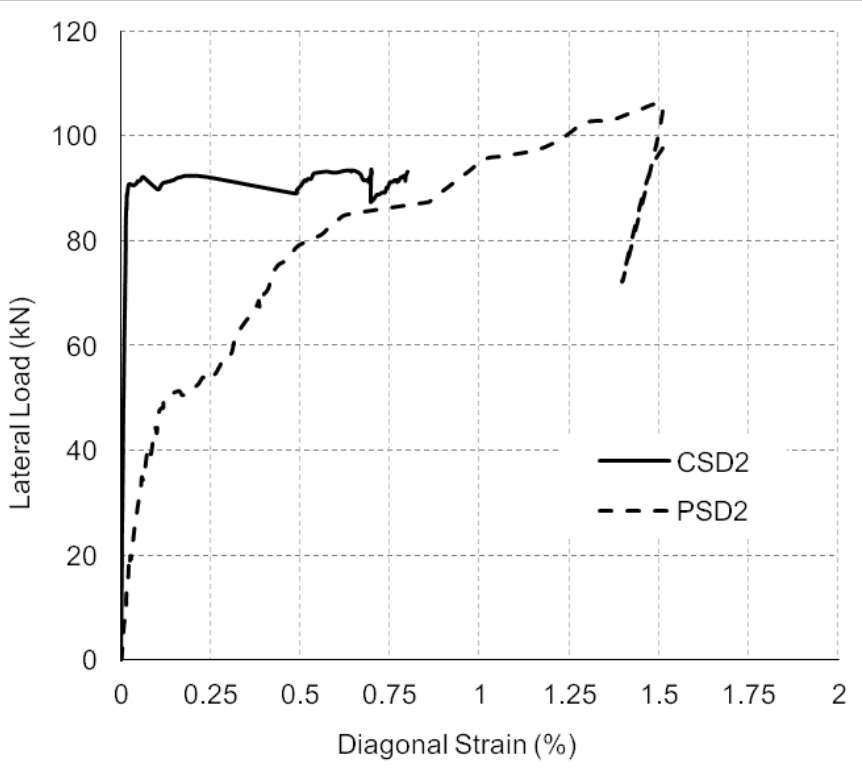

Fig. 14. Load-strain responses in diagonal FRP strips of retrofitted panels at point 2 on Fig. 9(a)

both CFRP and PET, but the rupture of PET sheet is very unlikely where as occasional rupture of the CFRP cannot be ruled out.

In the case of FRP grid system, mixed mode of failure can be seen in Fig.11 for both CFRP and PET-FRP reinforced walls, and their load-deformation responses are quite similar to each other [Fig. 12(c)]. This is due to the fact that beyond certain limit of FRP amount, the failure mode of masonry wall commutes from diagonal tension to predominantly flexural cracking irrespective of the type of FRP. Numerical modeling and analysis of masonry is the best tool to evaluate this threshold value. The horizontal strips of FRP played a crucial role here that restricted the wall from failing in a diagonal tension mode. These horizontal strips made the walls stronger in shear than in flexure. Though the vertical strips contributed in flexural strength to some extent, eventually it could not out strength the shear capacity, and caused the wall to fail in flexure. It is also interesting to make a comparison between Figs. 12(b) and (c) that once masonry walls are strengthened with CFRP in gird fashion, its brittleness in diagonal configuration changed into a ductile one. High FRP stiffness (11420 MN) did not change the overall stiffness of the masonry wall substantially, rather it helped the wall to deform as a composite system in such a way that can be compared as elastic-perfectly plastic deformation. But of course the deformability of high stiff CFRP will be less than that of PET as PET has higher deformation rate than CFRP. Another important point here to note that by increasing the amount and stiffness of FRP material on the surface of the wall does not necessarily increase the shear strength of the strengthened wall. Because it was point out earlier that a suitable material that has a moderate strength with a good deformability will be coherent with the fragile nature of masonry. One interesting observation that could be made here is that, in absence of vertical strips the wall would have been experienced in shear sliding along the planes that are not offset by the horizontal strips (Alcaino and Santa-Maria 2008). So it can be concluded that:

- Higher amount of FRP material bonded on the external surface of the masonry wall does not serve the purpose of strengthening; rather it will only increase the cost of the strengthening work and in some instance increases the stiffness of the masonry.

- Although the PET-FRP in grid system does not compromise with the overall ductility of the masonry, it is not an effective system of strengthening as it does not help much to enhance the masonry in-plane shear strength as compare to the diagonal system. Same is true for the CFRP gird system as well.

- $\quad$ FRP with high stiffness may change the masonry mode of failure from diagonal tension cracking into a flexural cracking. 


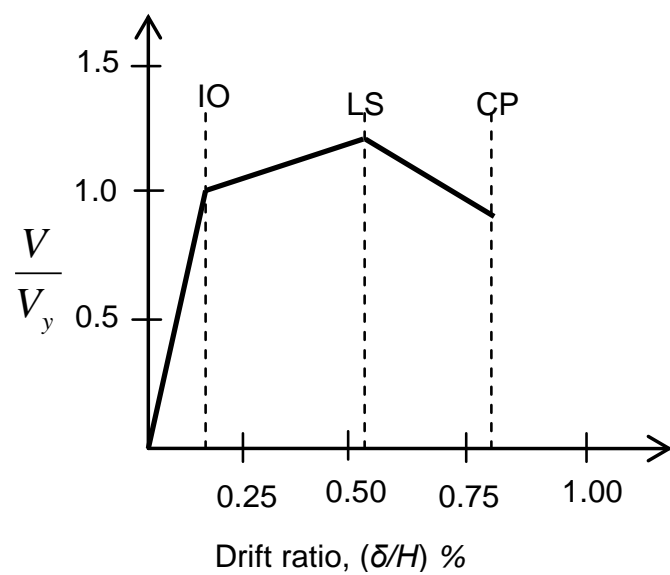

Fig. 15. Performance indices

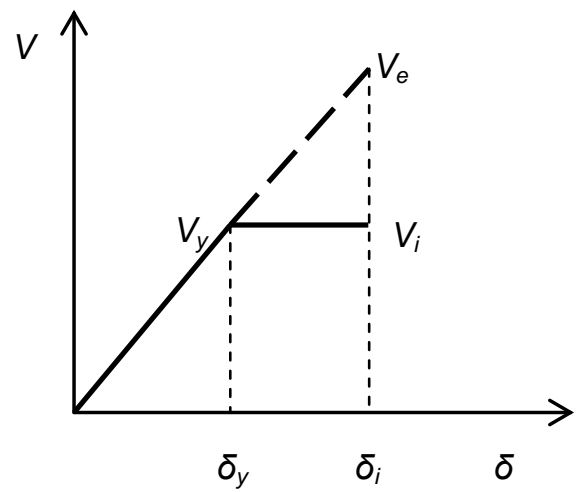

Fig. 16. Equal displacement rule for linear elastic analysis

As for the case of fully wrapped walls, ductility is hugely compromised for either of the FRP material i.e CFRP or PET. Although Fig. 12(d) does not depict the real deformation picture as it was stated earlier that these two walls underwent some rotation at their bottom and a premature failure at the grip was noticed. Even then, the deformability of these walls can be foreseen from these load-deformation plots. So, it can be said that though PET-FRP wall can resist more lateral load than its counterpart CFRP, either of them is not a good option for masonry strengthening as long as they are used in a fully wrapped manner.

One interesting point that came out from the analysis of these experimental results is that the contribution of FRP in masonry shear strength, irrespective of their types and arrangements, is only become manifest after a certain time which is somewhat like $60 \%$ of the peak strength and that can be attributed to the service loading condition. Only after that some potential cracks show up in the masonry and the FRP start to take part in contributing to shear. That is why, there is no significant difference in the initial stiffness of the unreinforced masonry as well as masonry with FRP [Figs. 12(a) - (d)] and that is why the initial strain in FRP is also very small (Fig. 14). So it can be concluded that FRP strengthening of the masonry can have only marginal effect on the shear strength at the service load condition but contribute a lot at some accidental overloading such as earthquake.

\section{ANALYSIS OF MASONRY PERFORMANCE}

Inelastic analysis of a structure becomes increasingly important with the emergence of performance-based engineering (PBE) as a technique for seismic evaluation and design (ATC-40 1996; SEAOC 1995; Terán-Gilmore et al. 2008, Magenes and Calvi 1997). PBE uses the prediction of performance to forecast decisions regarding safety and risk. In this approach the buildings and their components are designed with the objective of desired performance level (PL) for each seismic earthquake level, and with possible seismic hazards based on some acceptance criteria (FEMA 440, Abrams 2001).

\section{Performance of URM}

FEMA 356 provides a set of guidelines for URM walls that restricts the damage to three basic levels of performance. They are the immediate occupancy (IO) limit state, the life-safety (LS) limit state, and the collapse-prevention (CP) limit state as shown on the normalized force-deformation curve on Fig. 15. The CP limit state for URM buildings is related to the distress state in which the building is on the verge of partial or total collapse. Substantial damage to the structure has occurred, potentially including significant degradation in the stiffness and strength of the lateral-force resisting system, when the lateral resistance of a building drops by $20 \%$ i.e., $V_{C P}=0.8 V_{y}$. Here, $V_{C P}$ is the base shear in the building at the collapse prevention limit state, and the $V_{y}$ is the effective yield strength of the building determined from the capacity curve.

For seismic rehabilitation, simple nonlinear analysis is performed, based on a linear static approach, where lateral displacements are approximated in terms of member forces based on the equal displacement rule (i.e. elastic and 
inelastic displacements are the same for structures beyond yield strength shown in Fig. 16). With this assumption, as noted in Eq. (5), elastic design force due to earthquake and gravity loads, $V_{e}$, will be equal to the inelastic strength, $V_{i}$, times the ductility factor, $m$, which is defined as the inelastic deformation at a given limit state, $\delta_{i}$ divided by the yield deformation, $\delta_{y}$ [Eq. (6)]. FEMA 356 provides a set of ductility factors, $m$ for different limit states and for two different failure modes (rocking and shear sliding) of masonry. Table 4 provides the m-factors and drift ratios $(\delta / H)$ recommended by FEMA 356, along with the estimated performance of the shear walls in this study.

$$
\begin{gathered}
m V_{i} \geq V_{e} \\
\text { Here, } m=\frac{\delta_{i}}{\delta_{y}}
\end{gathered}
$$

The nonlinear force-displacement curve (also known as pushover capacity curve) of the component of the structure shall be replaced with an idealized relationship to calculate the effective lateral stiffness, $K_{e}$, and effective yield strength, $V_{y}$, of the building. Tri-linear idealization of the lateral force displacement curves of a URM wall as well as of a FRP strengthened walls are shown in Figs. 17(a) and (b), respectively. In this study, the target displacement, $\delta_{t}$, which is intended to represent the maximum displacement likely to be experienced during the design earthquake, has been simply assumed equal to, $\delta_{u}$, the deformation corresponding to ultimate shear strength. The detailed idealization technique and more accurate calculation of $\delta_{t}$ can be found in FEMA 440 and ATC 40. From the idealized curve, the effective lateral stiffness, $K_{e}$, shall be taken as the secant stiffness calculated at a base shear force equal to $60 \%$ of the effective yield strength $V_{y}$ of the structure. In the case of the unavailability of a pushover curve, a reasonable estimation of in-plane shear stiffness of URM is suggested here, by Eq. (7), provided all the parameters related to masonry are readily available (Al-Chaar 2002).

$$
K_{e}=\frac{1.2 \sigma_{n}}{\frac{H^{3}}{3 E_{m} I_{g}}+\frac{H}{A_{g} G_{m}}}
$$

Here, $I_{g}=$ Moment of inertia of the uncracked section of masonry; $E_{m}=$ Masonry elastic modulus; $G_{m}=$ Masonry shear modulus.

\section{Performance of Strengthened Masonry}

FEMA 356 and FEMA 440 guidelines do provide methods for estimating the strength and deformation capacity of existing URM walls and piers; however, they do not provide such information for components rehabilitated by FRPs. This is largely because such research data is limited. Only some strengthening techniques, design guidelines, and anchorage systems can be found elsewhere in the Model Code or Pre-standards like ACI 530, JSCE 2001, Euro Code 6, CNR DT 200 and ACI 440. From this experimental study, some of the parameters that were mentioned in the foregoing section regarding URM, are discussed here. Ductility factors, and collapse prevention are also addressed.

\section{Damage evolution and ductility capacity}

From Table 4, it is evident that many of the URM shear walls have poor performance in Life Safety (LS) and Collapse Prevention (CP) limit states. Once the masonry walls are strengthened by FRP strips, their performance get better. Masonry wall strengthened by diagonal PET-FRP behaves in a more ductile manner than the rest of the strengthening walls. It also shows a very good post peak collapse prevention behavior as the drift ratio is over 1.5 with a drift ratio more than the FEMA recommended value of 0.8 for URM. It is interesting to note that, when the shear walls are strengthened with the PET-FRP grid system, their stiffness increased and made the seismic ductility demand for CP much higher. On the other hand walls strengthened by CFRP show low percent drift ratio with a low ductility factor. As mentioned earlier, to be harmonized with masonry, a strengthening material needs to be identified that offers a moderate stiffness with a good ductile behavior. CFRP offers a higher stiffness with a 
low ductility performance, though having good enhancement of shear strength over PET-FRP. So, masonry externally reinforced with CFRP will not be a good alternative over PET-FRP.

Table 4. Performance of Experimental Shear Walls for Different Limit States

\begin{tabular}{|c|c|c|c|c|c|c|c|c|c|}
\hline \multirow{2}{*}{$\begin{array}{l}\text { Wall } \\
\text { Type }\end{array}$} & \multirow[t]{2}{*}{ References } & \multirow[t]{2}{*}{ Wall ID } & \multirow{2}{*}{$\begin{array}{c}\text { Performance } \\
\text { indeces }\end{array}$} & \multicolumn{3}{|c|}{ Performance Level } & \multirow{2}{*}{$\begin{array}{c}\text { Elastic } \\
\text { Stiffness } K_{e} \\
(\mathrm{~N} / \mathrm{mm})\end{array}$} & \multirow{2}{*}{$\begin{array}{l}\text { Post-yield } \\
\text { Stiffness } \\
\text { factor, } \alpha_{1}\end{array}$} & \multirow{2}{*}{$\begin{array}{l}\text { Softening } \\
\text { Stiffness } \\
\text { factor, } \alpha_{2}\end{array}$} \\
\hline & & & & IO & LS & $\mathrm{CP}$ & & & \\
\hline \multirow{22}{*}{$\sum_{S}$} & FEMA 356 & & $\mathrm{~m}$-factor & 1.0 & 6.0 & 8.0 & -- & -- & -- \\
\hline & & & $\%$ Drift, $(\delta / H)$ & 0.1 & 0.6 & 0.8 & & & \\
\hline & This study & RWS1 & $\mathrm{m}$-factor & 1.0 & 13 & 25 & 61,000 & 0.02 & 0.05 \\
\hline & & & $\%$ Drift, $(\delta / H)$ & 0.1 & 1.0 & 2.0 & & & \\
\hline & & RWS2 & m-factor & 1.0 & 14 & 23 & 62,000 & 0.02 & 0.07 \\
\hline & & & $\%$ Drift, $(\delta / H)$ & 0.1 & 0.6 & 1.1 & & & \\
\hline & Bosiljkov et al. & BNL4 & m-factor & 1.0 & 6.0 & 11.0 & 51,000 & 0.02 & 0.08 \\
\hline & (2004) & & $\% \operatorname{Drift},(\delta / H)$ & 0.1 & 0.8 & 1.5 & & & \\
\hline & & BNL6 & $\mathrm{m}$-factor & 1.0 & 18 & 32 & 33,000 & 0.01 & 0.03 \\
\hline & & & $\% \operatorname{Drift},(\delta / H)$ & 0.1 & 2.3 & 4.1 & & & \\
\hline & Magenes et al. & CL05 & $\mathrm{m}$-factor & 1.0 & 2.0 & 4.0 & 114,000 & 0.04 & 0.22 \\
\hline & (2008) & & $\% \operatorname{Drift},(\delta / H)$ & 0.1 & 0.3 & 0.5 & & & \\
\hline & & CL07 & m-factor & 1.0 & 2.0 & 3.0 & 20,000 & 0.01 & 0.32 \\
\hline & & & $\% \operatorname{Drift},(\delta / H)$ & 0.1 & 0.2 & 0.4 & & & \\
\hline & Modena et al. & $15 \_5$ & m-factor & 1.0 & 5.0 & 9.0 & 36,000 & 0.01 & 0.09 \\
\hline & (2005) & & $\% \operatorname{Drift},(\delta / H)$ & 0.3 & 1.4 & 2.6 & & & \\
\hline & Da Porto et al. & $15 \_7$ & $\mathrm{~m}$-factor & 1.0 & 6.0 & 11.0 & 54,000 & 0.01 & 0.07 \\
\hline & (2009) & & $\% \operatorname{Drift},(\delta / H)$ & 0.2 & 1.6 & 2.8 & & & \\
\hline & Fehling et al. & N1 & m-factor & 1.0 & 1.2 & 2.3 & 73,000 & 0.09 & 0.23 \\
\hline & (2007) & & $\% \operatorname{Drift},(\delta / H)$ & 0.1 & 0.1 & 0.2 & & & \\
\hline & Frumento et al. & $18 \_3$ & $\mathrm{~m}$-factor & 1.0 & 3.5 & 6.0 & 251,000 & 0.05 & 0.12 \\
\hline & (2009) & & $\% \operatorname{Drift},(\delta / H)$ & 0.1 & 0.2 & 0.4 & & & \\
\hline \multirow{8}{*}{  } & This study & PSD1 & $\mathrm{m}$-factor & 1.0 & 3.6 & 8.0 & 63,000 & 0.03 & 0.08 \\
\hline & & & $\% \operatorname{Drift},(\delta / H)$ & 0.3 & 1.1 & 2.3 & & & \\
\hline & & PSD2 & m-factor & 1.0 & 13 & 20 & 70,000 & 0.01 & 0.05 \\
\hline & & & $\% \operatorname{Drift},(\delta / H)$ & 0.1 & 1.2 & 1.8 & & & \\
\hline & & CSD1 & m-factor & 1.0 & 5.7 & 11 & 153,000 & 0.05 & 0.12 \\
\hline & & & $\%$ Drift, $(\delta / H)$ & 0.1 & 0.3 & 0.7 & & & \\
\hline & & CSD2 & m-factor & 1.0 & 3.7 & 8.0 & 149,000 & 0.09 & 0.15 \\
\hline & & & $\%$ Drift, $(\delta / H)$ & 0.1 & 0.2 & 0.5 & & & \\
\hline \multirow{8}{*}{ 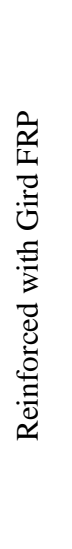 } & This study & PSG1 & $\mathrm{m}$-factor & 1.0 & 5.0 & 12 & 83,000 & 0.10 & 0.19 \\
\hline & & & $\%$ Drift, $(\delta / H)$ & 0.1 & 0.5 & 1.1 & & & \\
\hline & & PSG2 & m-factor & 1.0 & 6.0 & 21 & 99,000 & 0.13 & 0.15 \\
\hline & & & $\% \operatorname{Drift},(\delta / H)$ & 0.1 & 0.4 & 1.4 & & & \\
\hline & & CSG1 & m-factor & 1.0 & 6.0 & 18 & 810,000 & 0.05 & 0.06 \\
\hline & & & $\%$ Drift, $(\delta / H)$ & 0.1 & 16 & 0.3 & & & \\
\hline & & CSG2 & m-factor & 1.0 & 6.0 & 16.0 & 744,000 & 0.08 & 0.09 \\
\hline & & & $\%$ Drift, $(\delta / H)$ & 0.1 & 0.2 & 0.3 & & & \\
\hline
\end{tabular}



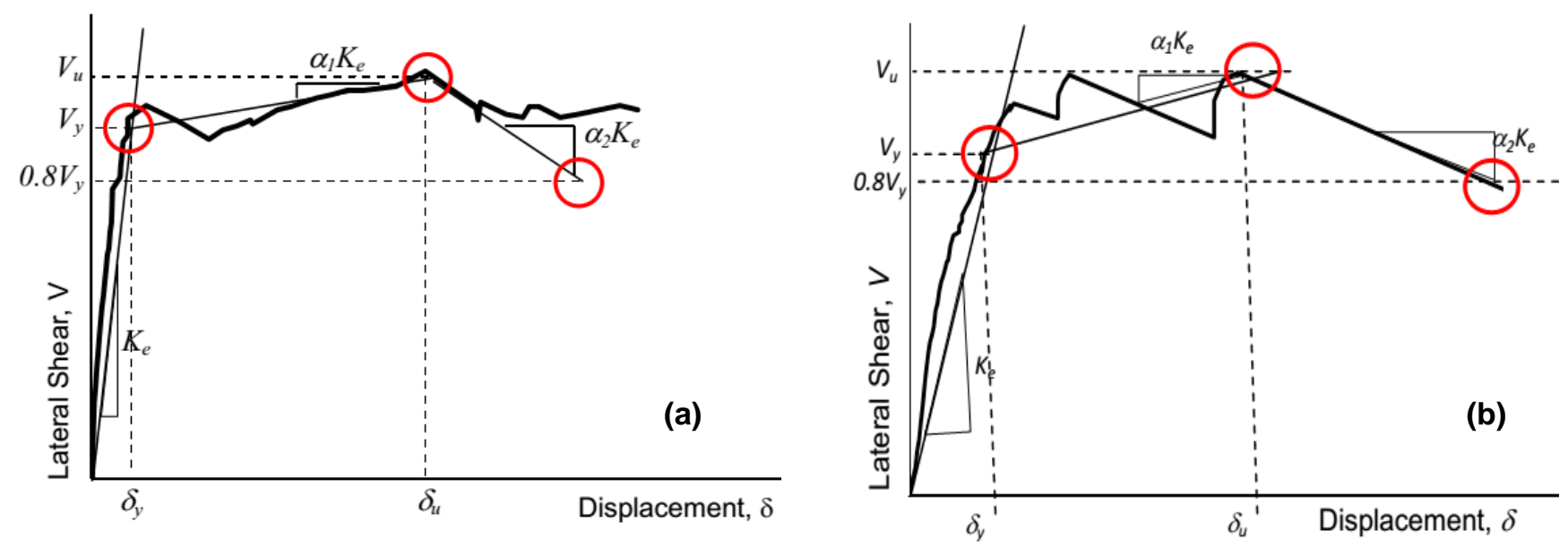

Fig. 17. Idealized force-displacement curve for (a) RWS1 and (b) CSD1 panels

\section{CONCLUDING REMARKS}

The in-plane shear behavior of twelve masonry walls having been strengthened by CFRP and PET-FRP sheets in three different configurations with similar boundary conditions have been studied under monotonic lateral loading in a quasi-static test facility. Vertical loads were applied at two points prior to lateral loading. Load-deformation characteristics were observed for each wall and subsequent damages were evaluated. Some of the performance criteria set by FEMA 356 are assessed. Based on the foregoing results and observations, the following remarks can be outlined:

- Two unreinforced reference walls failed in shear sliding and toe crushing preceded by a flexural cracking, which is largely seen as common failure mode of the URM wall with aspect ratio between 1 and 1.5 having a moderate percompression vertical load. For FRP strengthened masonry walls, the failure mode changed to predominantly a diagonal tension and toe crushing preceded by a flexural cracking where debonding was the most common phenomenon for the failure of FRP. In two occasions only the rupturing of CFRP were observed.

- The in-plane shear strength of the strengthened walls is considerably improved by using either of the FRPs but the ductility is compromised when CFRP is used as strengthening material. The experimental study demonstrates that PET-FRP has a better seismic performance than CFRP, as it shows a better ductile behavior than CFRP, especially in the post-peak region where there is a structural demand for integrity and margin of safety against collapse. Though the CFRP increases the shear capacity of a masonry wall, it substantially reduces the ductility of the wall, which may eventually cause an explosive type of masonry failure.

- The in-plane shear strengths observed in this experimental study are almost equal to each other for the cases where the amount of FRP was greater than a certain limit. This information will assist to some extent to develop an analytical model for FRP strengthened wall based on effective strain in FRP.

- The elastic stiffness of unreinforced masonry walls was largely modified by the use of FRP, externally bonded over the surface of the walls but it was observed that stiffness value beyond some specific range does not increase the in-plane shear strength of masonry and it will only increase the cost of strengthening works.

- Diagonal bracing with PET-FRP sheet can be the best option, where not only capacity enhanced but, at the same time, the wall is made quite ductile, substituting a catastrophic mode of failure by a ductile one.

- Another interesting point that is manifest from this experimental study is that the FRP strengthening of the masonry can have only marginal effect on the structural performance at the service load condition but contribute a lot at some accidental overloading such as earthquake, where the seismic demand is high.

- In all strengthening work, cost of the material and installation is prime concern of both engineers and builders. The cross-diagonal configuration requires least PET-FRP materials, whose material cost is less than CFRP, 
with the minimum amount of installation work among all the cases considered, including walls strengthened by CFRP strips. Wall fully covered by FRPs is not a viable option for external strengthening.

- Finally it has been shown that among the two FRPs used for strengthening of URM walls, PET-FRP has better seismic performance than CFRP especially at Life-Safely (LS) and Collapse Prevention (CP) state of the wall. However, further study is needed for the advancement of knowledge on FRP in general and on PET in particular concerning some of the unresolved issues that could not be addressed in this paper such as brick-FRP interface behaviour, optimum percent of FRP for masonry, delayed debonding and issue related to anchorage system of FRP with masonry. A concerted effort and a harmonized approach are necessary to make externally bonded FRPs as a lucrative solution for many historically valued masonry structures for retrofitting and rehabilitation purposes. Though the present work is not very exhaustive, it can be one step forward in achieving this goal.

\section{ACKNOWLEGDMENTS}

The authors sincerely acknowledge the financial assistance from CASR grant of KUET and from RONPAKU fellowship of JSPS to carry out this research. The authors are also thankful to Nippon Steel \& Sumikin Materials Co. Ltd. Japan and Maeda Kosen Co. Ltd. Japan, for their support in providing necessary materials for CFRP and PET-FRP, respectively, that have been used in this experiment.

\section{REFERENCES}

ACI 440. (2008). "Guide for the design and construction of externally bonded FRP systems for strengthening concrete structures.” American Concrete Institute, Farmington Hills, MI 48331 U.S.A.

ACI 530. (2002). “Building code requirements for masonry structures” ACI 530/ASCE 5/TMS 402.

ATC 40 (1996). "Seismic evaluation and retrofit of concrete buildings.” Applied Technology Council, Vol-1.

Ali, Q., Badrashi, Y. I., Ahmad, N., Alam, B., Rehman, S., and Banori, F. A. S.(2012) “ Experimental investigation on the characterization of solid clay brick masonry for lateral shear strength evaluation.” Int. J. of earth sciences and engr. 5(4), $782-791$.

Abrams, D. P. (2001). "Performance based engineering concepts for unreinforced masonry building structures.” Journal of Progress in Structural Engineering and Materials, Wiley Interscience, 3(1), 48-56.

Altin, S., Anil,O., Kara, M. E., and Kaya, M. (2007). “An experimental study on strengthening of masonry infilled RC frames using diagonal CFRP strips” Elsevier J. of Composites. Part B: Engineering.1-14.

Al-Chaar, G. (2002). ” Evaluating strength and stiffness of unreinforced masonry infill structures.” ERDC/CERL TR-02-1 report, Engineer Research and Development Center, US Army Corps. of Engineers.

Alcaino, P. and Santa-Maria, H. (2008), “Experimental Response of Externally Retrofitted Masonry Walls Subjected to Shear Loading” J. Compos. Constr., 12(5), 489- 498.

Akın, E., Özcebe, G., Canbay, E. and Binici, B. (2014). “A Numerical Study on CFRP Strengthening of Reinforced Concrete Frames with Masonry Infill Walls”, J. of Compos. Constr., 18(2), 04013034.

Anggawidjaja. D., Ueda. T., Dai. J., and Nakai. H. (2006). “Deformation capacity of RC piers wrapped by new fiber-reinforced polymer with large fracture strain.” Elsevier J. of Cement and Conrete. Compos. 28(2006), 914-927.

Benedetti, A. and Steli, E. (2006). “Analytical models for shear-displacement curves of unreinforced and FRP reinforced masonry panels.” Elsevier J. of Const. and Bldg. Mat.1-11.

Bosiljkov, V., Page, A. W., Bokan-Bosiljkov, V. and Z` arnic', R. (2003). "Performance based studies of in-plane loaded unreinforced masonry walls.” Masonry International 2003; 16(2):39-50.

Bosiljkov, V., Tomazevic, M., and Lutman, M. (2004). “Optimization of shape of masonry units and technology of construction for earthquake resistant masonry buildings: research report-part one and two.” ZAG Ljubljana, Slovenia. 
Bosiljkov, V., Page, A. W., Bokan-Bosiljkov, V., and Z`arnic', R. (2008). "Review paper, progress in structural engineering and material: structural masonry evaluation of the seismic performance of brick masonry walls.” Struct. Control Health Monit. 17,100-118.

Burgoyne, C. and Balafas, I. (2007). "Why is FRP not a financial success?”, FRPRCS-8, University of Patras, Patras, Greece, pp.1-10.

CNR-DT200. (2013). "Guide for the Design and Construction of Externally Bonded FRP Systems for Strengthening Existing Structures.” CNR-DT 200 R1, Italian National Research Council, Italy.

Da Porto, F., Grendene, M., and Modena, C. (2009). “Estimation of load reduction factors for clay masonry walls.” Earthq. Eng. Struct. Dyn. 38:1155-1174.

Dizhur, D., Griffith, M. C., and Ingham, J. M. (2013). “In-plane shear improvement of unreinforced masonry wall panels using NSM CFRP strips.” J. Compos. Constr., 17(6), 04013010.

Eurocode 6 (2005). "Design of masonry structures - Part 1-1: General rules for reinforced and unreinforced masonry structures”. EN 1996 -1 -1: 2005, CEN, Brussels.

Ehsani, M. R., Saadatmanesh, H., and Al-Saidy, A. (1997). "Shear behavior of URM retrofitted with FRP overlays.” J. Compos. Constr., 1(1), 17- 25.

ElGawady, M. A., Lestuzzi, P., and Badoux, M. (2005). “ Performance of masonry walls under in-plane seismic loading.” TMS Journal, 23(1),85-104.

ElGawady, M. A., Lestuzzi, P., and Badoux, M. (2007). "Static cyclic response of masonry walls retrofitted with fiber-reinforced polymers” J. Compos. Constr., 11(1), 50-61.

FEMA 274. (1997). "NEHRP commentary on the guidelines for the seismic rehabilitation of buildings” for building seismic safety council by ATC 33, Washington, D.C.

FEMA 356. (2000). "Prestandard and commentary for the seismic rehabilitation of buildings.” Federal emergency management agency, Washington, D.C.

FEMA 440. (2005). “Improvement of nonlinear static seismic analysis procedures.” Federal emergency management agency, Washington, D.C.

Fehling, E., Stuerz, J., and Emami, A. (2007). "Tests results on the behaviour of masonry under static (monotonic and cyclic) in plane lateral loads” Tech. report of the col. res. pro. ESECMaSE, eliverable D7.1a. Germany.

Frumento, S., Magenes, G., Morandi, P., and Calvi, G. M. (2009). "Interpretation of experimental shear tests on clay brick masonry walls and evaluation of q-factors for seismic design.” IUSS Press, Pavia.

Foraboschi, P. (2009). “Coupling effect between masonry spandrels and piers.” Mat. and Str. 42, 279-300.

Foraboschi, P., and Vanin, A. (2013). "New methods for bonding FRP strips onto masonry structures: Experimental results and analytical evaluations.” Comp.: Mech., Comp., Appli. An Int. J., 4(1), 1-23.

Foraboschi, P. (2015). “Analytical model to predict the lifetime of concrete members externally reinforced with FRP.” Theoretical and Applied Fracture Mechanics, 75(1), 137-145.

Hamid, A., EI-Dakhakhni, W. W., Hakam, Z., and Elgaaly, M. (2005). "Behaviour of composite unreinforced masonry-fiber-reinforced polymer wall assemblages under in-plane loading.” J. Compos. Constr., 9(1), 73-83.

Hansen, K. F. (1999). “Bending and shear test with masonry.” SBI bulletin 123, Danish Building research Institute, Hørsholm, Denmark.

JSCE (2001). “Recommendation for Upgrading of Concrete Structures with use of Continuous Fiber Sheets.”

Concrete Engineering Series 41, Japan Society of Civil Engineers, Tokyo, Japan.

Magenes, G., and Calvi, M. (1997). “In-plane seismic response of brick masonry walls.” Earthquake Engineering and Structural Dynamics, 26, 1091-1112. 
Magenes, G., Morandi, P., and Penna, A. (2008). “Tests results on the behaviour of masonry under static cyclic in plane lateral loads.” Tech. report of the coll. res. pro. ESECMaSE, Uni. of Pavia, Italy.

Marcari, G., Manfredi G., Prota A. and Pecce, M. (2007). “In-plane shear performance of masonry panels strengthened with FRP.” Elsevier J. of Comp. Part B 38, 887-901.

Modena, C., Da Porto, F., and Garbin, F. (2005). "Ricerca sperimentale sul comportamento di sistemi per muratura portante in zona sesmica: draft 2005/01.” University of Padua, Italy.

Maeda Kosen Co. Ltd. Japan. (2005). “Fiber Frontier System” (http://www.maedakosen.jp/) (May 10, 2013).

Nippon Steel \& Sumikin Materials Co. Ltd. Japan. (1997). “Construction Materials: FORCA Towsheet” (http://www.nck.nsmat.co.jp/english.html) (April 6, 2013).

Rahman, A. and Ueda, T. (2014). "Experimental investigation and numerical modeling of peak shear stress of brick masonry mortar joint under compression.” J. Mat. C. Eng., 26(9), 04014061,1-13.

Salmanpour, A. H., Mojsilovic, N., and Schwartz, J. (2013). "Deformation capacity of unreinforced masonry walls subjected to in-plane loading: a state-of-the-art review.”Int. J. of Adv. Struc. Eng. Springer 5(22), 1-12.

SEAOC (1995). “Performance Based Seismic Engineering.” Report prepared by Structural Engineers Association of California.

Stratford, T., Pascale, G., Manfroni, O., and Bonfiglioli, B. (2004). "Shear strengthening masonry panels with sheet glass-fiber reinforced polymer”. J. Compos. Constr., 8(5), 434- 443.

Shrestha, J., Ueda, T., and Zhang, D. (2014). "Durability of FRP concrete bonds and its constituent properties under the influence of moisture conditions.” J. Mat. C. Eng., 0899-1561/A4014009(14).

TNO. (2004). "Shear test on masonry panels; literature survey and proposal for experiments. TNO Building and Construction Research. 2600 AA Delft.

Terán-Gilmore, A., Oscar Zuñiga-Cuevas, Z., and Ruiz-García, J. (2008) “Model for the nonlinear analysis of confined masonry buildings” The $14^{\text {th }}$ World Conf. on Earthquake Engineering, Beijing, China.

Tomaževič, M., and Gams, M. (2009). "Shear resistance of unreinforced masonry walls.” Ingineria Sismica, 26: 3, 5-18.

Wang, Q., Chai, Z., Huang, Y., Yang, Y. and Zhang, Y. (2006) "Seismic shear capacity of brick masonry wall reinforced by GFRP.” Asian Journal Of Civil Engineering (Building And Housing), 7(6), 563-580.

Zhuge, Y. (2010). “FRP-retrofitted URM walls under in-plane shear: review and assessment of available models” J. Compos. Constr., 14(6), 743- 753. 